\title{
CAREER CONCERNS, MATCHING, AND OPTIMAL DISCLOSURE POLICY*
}

\author{
BY ARIJIT MUKHERJEE ${ }^{1}$ \\ Michigan State University, U.S.A., BatesWhite, LLC, U.S.A.
}

\begin{abstract}
Raiders may suffer from information disadvantage since the current employer is often better informed about his workers' quality. When workers have career concerns and matching influences productivity, the initial employer can strategically disclose information to influence incentives and matching efficiency. Long-term complete contracts induce full disclosure when raiders are perfectly competitive. The optimal short-term contract induces full disclosure if raiders are perfectly competitive, and the workers are risk neutral and are not liquidity constrained. These conditions are not only sufficient but also "almost necessary" for full disclosure. Partial disclosure may be optimal if any of these conditions is relaxed.
\end{abstract}

\section{INTRODUCTION}

Sequential contracting with multiple employers is a common feature of the modern labor market. Job-to-job flow constitutes a substantial proportion of total job separations in United States. Farber (1999) shows evidence from Current Population Survey data that "over $28 \%$ of the workforce reports having been on their job for 1 year or less over the 1973-93 period." According to Fallick and Fleischman (2004), "on average $2.6 \%$ of employed persons change employers each month, a flow twice as large as that from employment to unemployment."

Employment relations often terminate due to raids (i.e., poaching), in which a raiding firm tries to bid away workers from other firms. Autor (2001) reports "between $11 \%$ and $18 \%$ of Temporary Help Service workers placed on assignment in a calendar month are directly hired by clients." However, when hiring an experienced worker (agent), a raiding firm (downstream principal) may face an informational disadvantage compared to the initial employer (upstream

\footnotetext{
* Manuscript submitted July 2006; revised May 2007.

${ }^{1}$ This article is based on Chapter 1 of my Ph.D. dissertation (Mukherjee, 2005b) in Northwestern University. I would like to thank Michael Whinston for his invaluable guidance and support throughout this project. I am also indebted to Alessandro Pavan for his extremely helpful suggestions. I have greatly benefited from numerous discussions with Scott Schaefer and Dale Mortensen. For their helpful comments, I would like to thank Maria Goltsman, Piotr Kuszewski, Espen Moen, Eugene Orlov, Marco Ottaviani, Marcin Peski, Scott Stern, Michael Waldman, Jan Zábojník, Fan Zhang, and seminar participants in Cornell University, Indian School of Business, Northwestern University, Rutgers University, Fall 2004 Midwest International Economics and Economic Theory Meeting, St. Louis, and 2006 North American Summer Meetings of Econometric Society, Minneapolis. All the errors that remain are mine. Please address correspondence to: Arijit Mukherjee, Department of Economics, Michigan State University, 110 Marshall Adams Hall, East Lansing, MI 48824, U.S.A. Phone: 517-355-7583. E-mail: arijit@msu.edu. URL:www.amukherjee.net.
} 
principal). ${ }^{2}$ In fact, the latter typically possesses better information about the productivity (or type) of the agent as a result of having observed the agent's past performance. In such an environment, the downstream principal's offer will be based on her "beliefs" about the agent's type. This offer affects not only the agent but also the upstream principal. Indeed, the wage in the upstream relationship may incorporate the surplus the agent expects from downstream relationships. As shown in Calzolari and Pavan (2006), an upstream principal, who anticipates her agents to contract also with downstream principals, has strong incentives to commit up front to a disclosure policy that specifies what information will be disclosed to the rival firms.

Strategic information disclosure is particularly relevant when the agent has career concerns and matching between firms and workers is important. In the presence of career concerns, the agent's current performance influences his future wage. Thus, disclosure of information about the agent's performance may sharpen his current incentives. It also enhances the matching efficiency between the agents and the future employers by removing the information asymmetry in turnover. At the same time, more disclosure exposes the agent to an additional human capital risk, since his future wage fluctuates more with his current performance. Hence, the optimal disclosure policy trades off the benefits from sharper incentives and efficient matching with the cost of human capital risk.

The purpose of this article is to formalize this trade-off, and to derive implications for the design of optimal disclosure policies. In contrast with the existing literature that looks at specific channels of information disclosure (e.g., promotion [Waldman, 1984, 1990], rank-order tournaments [Zábojník and Bernhardt, 2001]), I attempt to answer the question that if the firm can commit to any arbitrary channel of information disclosure, what are the key economic effects that govern its choice, and how do they influence the optimal disclosure policy.

I consider a two-period model where an upstream firm employs an agent whose ability is unknown to all parties. The agent works under an explicit pay-perperformance contract. At the end of the first period, the firm discloses information about the agent's performance to the potential future employers. In the second period, the agent may be raided by the rival firms where he is likely to be more productive (i.e., a better match). The initial employer then decides whether to match the best offer from the raiders or to let the agent leave. I assume that the initial employer can credibly commit to an information transmission mechanism (henceforth referred to as a "disclosure policy"), which maps the agent's performance measure into signals disclosed to other employers.

My first result shows that, if the initial employer can use a long-term complete contract, that is, if she can commit to a second-period wage and severance payment (or "bond" payment), her optimal contract will always induce full information disclosure under perfect competition in the raider market. ${ }^{3}$

\footnotetext{
${ }^{2}$ In what follows, I adopt the convention of referring to the agent (he) as the worker and the principal (she) as the firm.

${ }^{3}$ A severance payment is a transfer payment by the firm to its employee upon termination of employment. I will allow for both positive and negative severance payments, where a negative severance payment is interpreted as a transfer from the agent to the firm.
} 
The intuition behind this result is the following. Since the agent is more productive with the raiders, matching efficiency requires turnover for all agent types. With partial disclosure, the firm holds better information about the type of the agent. Accordingly, the firm will match the best offer from the raiders if and only if she finds it worthwhile to do so (given her possession of superior information). This leads to a potential adverse selection problem that restricts turnover. Full disclosure ensures the maximum possible matching surplus in the raiding game by eliminating the adverse selection problem. If the raider market is perfectly competitive, the raiders necessarily earn zero profit, and the entire matching gain is offered to the agent. The firm can, in turn, extract this gain up front by reducing the wage paid to the agent.

However, full disclosure may come at the cost of exposing the agent to a greater human capital risk by making his future wages more sensitive to his current performance. If the agent is risk averse, the firm may need to pay a higher risk premium to make the agent willing to accept the contract. This additional premium, in principle, may outweigh the additional gains from efficient matching that are derived from full disclosure. But this is not the case when the firm can offer long-term complete contracts. By adjusting the second-period wage and severance payment, the firm can guarantee that the agent's payoff in every state of the world remains exactly the same as in the absence of full disclosure. By doing so, the firm insures the agent from the additional human capital risk without distorting the incentive provisions, and hence, eliminates any need for an additional risk premium.

In some cases, however, long-term contracts may not be feasible. I define a short-term performance contract as a special case of long-term complete contract, in which the firm has no commitment power over the second-period wage and severance payment, and offers a deterministic first-period wage for every output realization. My second result shows that, when the raider market is perfectly competitive, the optimal short-term performance contract induces full disclosure if (i) the agent is risk neutral and (ii) he does not face any liquidity constraint.

The intuition for this result is similar to the former one, but two additional issues need to addressed. First, a short-run contract may not completely insure the agent from the human capital risk. But, if the agent is risk neutral, the firm does not need to pay any risk premium for the human capital risk induced by disclosure (this observation suggests that the impossibility of writing long-term contracts has no impact under risk neutrality). Second, the impossibility of committing to future wages and severance payments also implies that the initial employer can only extract the matching gains by lowering the period-one wages of the agent. If the agent is liquidity constrained, this rent extraction mechanism may fail. $^{4}$

\footnotetext{
${ }^{4}$ Under long-term contracts, liquidity constraints do not matter since the firm can lower the periodtwo wages/severance payments for rent extraction. In period-two, the agent can use (part of) the wage he receives from the raider to accommodate a potentially negative wage/severance payment.
} 
The two results discussed above serve as a benchmark for the optimality of full disclosure. A partial converse is also true. If any of the three conditions in these results is violated, one can find preferences for the agent and parameter values for which full disclosure is no longer optimal. In this sense, the above conditions are not only sufficient, but also "almost" necessary for the optimality of full disclosure. To illustrate this issue, I relax each of these conditions one at a time. This analysis is particularly useful in delivering key economic intuitions behind the role of each of these conditions.

First, consider the assumption of perfect competition in the raider market. Suppose, in contrast, that there is only a monopsonistic raider bidding for the agent. In that case, under full disclosure, the raider appropriates the entire efficiency gain from transferring the agent to her firm. On the other hand, by partially pooling low-ability agents with those of high ability, the initial employer can sell a "lemon" at the price of a "plum," and hence, extract a higher surplus from the raider. The initial employer may therefore find it optimal to commit to a policy that discloses only noisy information regarding the agent's past performance. ${ }^{5}$ In other words, partial disclosure may induce the raider to leave information rent with the low-type agent that the firm can extract up front. ${ }^{6}$

Second, assume that the firm cannot offer long-term contracts and that the "no liquidity constraint" assumption is violated. Thus, the firm may not be able to make the agent pay up front in return for a higher wage later in his career. Suppose that career concerns under full disclosure are so strong that the agent puts in effort even when period-one wages are set at their feasible minimum. Hence, no further extraction of matching surplus is feasible. In such a setting, partial disclosure may allow the employer to retain some of the good workers at low wages, because, with the available information, the labor market may not offer higher wages due to adverse selection in turnover.

Finally, the agent's risk aversion might lead to partial disclosure if it requires a large risk premium that outweighs the gains from matching. The higher is the degree of risk aversion and/or the lower are the matching gains, the less transparent is the optimal disclosure policy.

As discussed in Calzolari and Pavan (2006), the disclosure mechanism is modeled as a signaling mechanism that generates signals according to a pre-specified probability distribution, conditional on the agent's performance. Though this may seem rather abstract, such a mechanism captures quite a few real life examples of disclosure policies. For instance, publicly announced promotions can be thought of as signals of an agent's quality to the outsiders (Waldman, 1984). Job design can also be thought of as a signaling mechanism. The firm can design jobs in such a way that she makes the agent's quality visible to outsiders with an appropriate degree of noise. Loveman and O'Connell (1996) provide a case study of a Silicon Valley firm, HCL America. They argue that retention of software developers is

\footnotetext{
${ }^{5}$ A similar result is obtained by Calzolari and Pavan (2006).

${ }^{6}$ The resulting loss in turnover efficiency due to partial disclosure does not affect the firm's payoff, because the monopsonist raider retains the entire available matching gains.
} 
one of the biggest challenges for the firm. The management believes that too much interaction between the engineers and the clients is one reason behind such a high turnover, because the "engineers working with a client on site frequently received job offers from the client." One strategy that the management is contemplating is to replace on-site contracts with projects run in their own facilities "to reduce contact between engineers and clients so as to curtail the job offer." Once again, one can interpret such a strategy as a particular choice of an information transmission mechanism. In an on-site contract, the client (the raider) can obtain nearly perfect information about the quality of a worker. Bringing projects to its own facility allows HCL America to send only a noisy signal about its worker's quality, and thereby, possibly deter raids.

The rest of the article is organized as follows. Section 2 provides a literature review. The model is described in Section 3, and the main results are proved in Section 4. Section 5 discusses the impact of relaxing the assumptions in the benchmark results and some characterization of the optimal noisy disclosure policy. Some robustness checks and extensions are considered in Section 6. Section 7 concludes. Proofs are omitted in the main text and provided in the Appendix.

\section{RELATED LITERATURE}

Ever since the seminal work by Fama (1980), many authors have contributed to the literature on career concerns. Holmstrom (1982) provides a classic treatment of informal incentives based on career concerns. He develops a model to show that, in absence of any formal pay-contingent contract, a worker's reputational concerns can be a solution to an agency problem. Dewatripont et al. (1999a, 1999b) generalize this model and study the impact of information quality on the power of career concern incentives. In contrast to this article, most of these works assume no information asymmetry between the current and the prospective employers. (See also Scharfstein and Stein, 1990; Gibbons and Murphy, 1992; Jeon, 1996; Ortega, 2003.)

Informational asymmetry between current and future employers opens up a role for strategic information transmission. Some authors have studied the role of information transmission in the context of certain specific information disclosure channels, such as promotions (Waldman, 1984) and rank-order tournaments (Zábojník and Bernhardt, 2001; Koch and Peyrache, 2003b). In contrast, I allow the firm to choose an arbitrary channel of information disclosure and investigate the determinants of a firm's disclosure decision.

Calzolari and Pavan (2006) are the first to endogenize the information structure in a sequential common agency game. They characterize the optimal disclosure policy in a game where trade surplus in the downstream relationship may depend on both the agent's exogenous private information and the endogenous information on the upstream principal's trade decisions. They find that it is always in the interest of the upstream principal to distort information. This is in contrast with this article where no screening contract is feasible, as the agent's type is unknown 
to all parties. Moreover, I find that full disclosure can be optimal under certain conditions, whereas this is never the case in their paper.

Koch and Peyrache (2003a) model a sequential labor contract scenario where the upstream principal has an informational advantage over downstream principals. Similar to this article, they highlight the role of disclosure in boosting career concerns. However, their paper differs from this article in several ways. As in Calzolari and Pavan (2006), they allow for screening contracts and find that the first principal will always disclose a noisy signal about the worker's quality. They also differ from this article in certain key assumptions. In their model, a worker's future wages do not increase with his performance since output fully reveals his type. Hence, the firm may decide to pool the agents' performances to create reputational incentives. In addition, they restrict the contract space to renegotiationproof deterministic contracts. Another important assumption in their paper is that the worker's turnover is exogenous (this is also assumed in Calzolari and Pavan, 2006). I show that endogenizing the worker's turnover decision can lead to an adverse selection problem, which feeds back to the design of the optimal disclosure policy for the upstream principal.

In a related paper, Albano and Leaver (2004) focus on the impact of transparency decision of public sector organizations where wages are rigid. They find that transparency is unlikely to be the optimal policy unless certain conditions about the worker's productivity are satisfied. In contrast, I consider a different environment where wages are flexible and derive a different set of results where transparency can indeed be optimal irrespective of the degree of productivity differences across workers.

This article is also related to the literature on adverse selection in labor markets (Greenwald, 1986). Several authors have noted how the adverse selection problem may lead to a winner's curse problem in worker's turnover (Lazear, 1986; Waldman, 1990; Blanes-i-Vidal, 2002). These studies assume that the impact of the winner's curse effect is exogenous to the upstream principal. In my analysis, this effect originates endogenously, and the upstream firm can manipulate the impact of this effect through her choice of disclosure policy.

\section{THE MODEL}

Players. I consider a two-period principal-agent model. An agent, $A$, is employed by the upstream firm, $F$, in the first period of his career. In the second period, $A$ may get offers from the potential employers or "raiders" $R_{1}$ and $R_{2}$. The raiders are identical firms, and bid competitively to hire the agent. After observing the raiders' bid, $F$ submits a counteroffer to $A$. Given the offers from $F$ and the raiders, $A$ decides which employer to work for in the second period.

Technology. In the two periods of his life, $A$ is assigned to two different tasks, which differ in their underlying technologies. In the first period, $A$ 's output, $y_{1}$ $\in Y=\left\{y_{L}, y_{H}\right\}$, where $y_{L}<y_{H}$, is stochastic and depends on effort and ability. The agent's ability, $a \in\{\underline{a}, \bar{a}\}$, is unknown to all parties, and $\underline{a}<\bar{a}$. The prior distribution of $a$ is $\operatorname{Pr}(a=\bar{a})=p$.A puts in effort $e \in\{0,1\}$ that is observed only by 
$A$ and is, therefore, not contractible. ${ }^{7}$ Output is contractible but not observed by the raiding firms. ${ }^{8}$

Let $\bar{P}_{1}=\operatorname{Pr}\left(y_{H} \mid e=1, \bar{a}\right)$ be the probability of obtaining high output when a high-ability agent puts forth effort $e=1 . \bar{P}_{0}, \underline{P}_{1}$ and $\underline{P}_{0}$ are defined in the same way. Let $\bar{P}_{1}>\underline{P}_{1}$ and $\bar{P}_{0}>\underline{P}_{0}$, i.e., for all effort levels, high output is more likely if $A$ is of high ability. Moreover, $\bar{P}_{1}>\bar{P}_{0}$, and $\underline{P}_{1}>\underline{P}_{0}$, i.e., irrespective of ability, effort increases the probability of obtaining high output. Let $P_{1}=\operatorname{Pr}\left(y_{H} \mid e=1\right)$, and $P_{0}=\operatorname{Pr}\left(y_{H} \mid e=0\right)$. Note that the previous assumptions imply $P_{1}>P_{0}$, i.e., the total probability of producing high output increases with effort.

There is no moral hazard problem in the second period. Here, $A$ is assigned to a task where output is a function of ability only. To simplify matters, assume that for $F$ the output of an agent with ability $a$ is $y_{2}=a$. For $R_{1}$ and $R_{2}$, the agent is a better match. $A$ is at least as productive in a raider's firm as he is in $F$, irrespective of his ability. Given an ability level $a$, $A$ 's output in a raider's firm is $a+m$, where $m(>0)$ is the matching factor. ${ }^{9}$ The value of $m$ is known to all players. ${ }^{10}$

Contract Design. $\quad F$ can provide incentives to $A$ through two channels. First, she can rely on the agent's career concerns. As the agent's ability is unknown, prospective employers update their beliefs about $A$ 's ability conditional on the information they receive on $y_{1} . F$ can strategically disclose information to the raiders to manipulate their posterior belief, and hence, their subsequent wage offer to $A$. Second, the firm can pay for performance, i.e., choose wage payments conditional on output in each period. ${ }^{11}$

In the most general specification of the model, $F$ offers a long-term complete contract to $A$ at the beginning of period one. The contract specifies for: (i) wages in period one contingent on period-one output, (ii) a disclosure policy (which I shall formally define later), (iii) wages in period two if $A$ continues to work under $F$, and (iv) a severance payment in case $A$ leaves the firm.

Let the contract be denoted by a mapping $\phi_{F}=\left(\phi_{F}^{1}, \phi_{F}^{2}\right)$, where $\phi_{F}^{1}: Y \rightarrow$ $\Delta(\mathrm{X} \times \mathrm{W})$, and $\phi_{F}^{2}: Y \times X \rightarrow \mathrm{W}^{2}$.

\footnotetext{
${ }^{7}$ As I will discuss in Section 4, unobservability of effort is not essential for the benchmark results on full disclosure. However, I maintain this assumption primarily for two reasons: (i) The incentive implications of the career concerns effect are more relevant when the unobserved effort creates a moral hazard problem. (ii) When the agent is liquidity constrained or risk averse, the moral hazard problem has interesting effects on the optimal disclosure policy (see Section 5).

${ }^{8}$ The discrete nature of the problem is not important for the main results, and it is assumed here only for the sake of analytical simplicity. See Mukherjee (2005a) for an extension of the model to the case of continuous output, effort, and ability.

${ }^{9}$ To motivate this assumption, one can think in the following terms. Firms differ in terms of their matching factors, but only the ones with the highest factor care to bid, as raiders compete in prices to win the agent. I assume that the highest value of this factor is nonnegative.

${ }^{10}$ One can easily generalize the model by assuming a more complex nature of the matching gain $m$. For example, $m$ may be stochastic, may depend on $a$, and so on. The results of the model are immune to such changes. I will briefly revisit this issue in Section 6.

${ }^{11}$ It is important to note that the feasibility of output contingent payments in each period is a departure from the canonical career concerns model (Holmstrom, 1982), and it creates room for strategic interaction between the two channels of incentives (see Gibbons and Murphy, 1992).
} 
$\phi_{F}^{1}$ maps $y_{1}$ into a joint probability distribution over $X$, a set of signals that $F$ discloses to $R_{1}$ and $R_{2}$, and a set of possible wage payments, $W \subseteq \mathbb{R}$. The first-period wage, $w_{1}\left(y_{1}\right) \in W$, is paid at the end of period one. The mapping $\phi_{F}^{1}$ also induces a disclosure policy $\delta: Y \rightarrow \Delta \mathrm{X}$. Given $y_{1}, F$ sends a signal, $x \in$ $X$, according to the distribution, $\delta\left(x \mid y_{1}\right)$. One can think of the disclosure policy as a "garbling" of $y_{1}$ that $F$ allows the raiders to observe. The definition of such a contract implicitly assumes that the firm can credibly commit to a pay-perperformance contract as well as a disclosure policy. If any information is revealed, it is revealed to both raiders. There is no information asymmetry between the raiding firms. ${ }^{12}$

$\phi_{F}^{2}$ maps the tuple $\left(y_{1}, x\right)$ to a wage payment, $w_{2} \in W$, if $A$ continues to work for $F$ and a severance payment, $s \in W$, if he leaves. Both payments are made at the end of period two. ${ }^{13}$ Note that, like wages, severance payments can also be negative, implying a transfer from the agent to the firm when a raid is successful. I also assume that the agent cannot credibly reveal his wages to the raiding firm. ${ }^{14}$

In contrast, when only a short-term performance contract is feasible, the firm is assumed to have no commitment power over the second-period wages and severance payments. I define a short-term performance contract as a special case of a long-term complete contract, where $w_{2}=s=0, \forall\left(y_{1}, x\right) \in Y \times X$, and the period-one wage is a deterministic function of the realized output. A short-term performance contract specifies only the (i) wages in period one and (ii) a disclosure policy as defined above. ${ }^{15}$

In the second period, the wage (or "bid"), $b_{i}$, that raider $R_{i}$ offers is a mapping from the set of signals that he may receive to the set of wages, $W$; i.e., $b_{i}: X \rightarrow$ $W ; i=1,2$. Let $B$ be the set of all such mappings.

Observing $b_{1}$ and $b_{2}, F$ can match the best offer. Based on output $y_{1}$ and bids $\mathbf{b}=\left(b_{1}, b_{2}\right), F$ offers a new pair $\left(\hat{w}_{2}\left(\mathbf{b}, y_{1}\right), \hat{s}\left(\mathbf{b}, y_{1}\right)\right)$ such that $\hat{w}_{2} \geq w_{2}$ and $\hat{s} \geq s$. Thus, the firm cannot take away the offer that the initial contract specifies, but she can offer a better deal to the agent. ${ }^{16}$

\footnotetext{
${ }^{12}$ As I will describe later, the raiders' bidding behavior is the same as that in a common value first-price ascending auction. Thus, it is indeed optimal for the firm to publicly reveal the signal instead of revealing different signals to different raiding firms (see Milgrom and Weber, 1982).

${ }^{13}$ Observe that $w_{2}$ does not depend on $y_{2}$ in the contract specification presented here. This restriction is without any loss of generality since there in no moral hazard problem in period two.

${ }^{14}$ Almost all of the results in this article will hold even if the agent has the option of revealing his wage directly to the raider to signal his type. I will revisit this issue in Section 6.

${ }^{15}$ Note that, in a short-term contract, $F$ can still commit to a disclosure policy even though the second period payments (conditional on the realized signal) are not contractible. One can motivate this assumption in the context of job design. Suppose every job, depending on its underlying technology, reveals some information about $A$ 's ability to the raiders. $F$ may not directly observe what information the raiders have, and hence, cannot write a complete contract. But she can influence the flow of information by choosing a particular job design.

${ }^{16}$ As under a short-term performance contract $s=0$, it is clearly a dominated strategy for $F$ to offer $A$ a positive payment for leaving the firm following a successful raid. Thus, under short-term performance contracts, $\hat{s}=0$.
} 
After receiving the second-period offers, $A$ works for the firm that offers the highest net transfer. ${ }^{17} \mathrm{I}$ assume that, if $F$ 's counteroffer makes $A$ indifferent between staying and leaving, $A$ stays with $F$. Otherwise, $A$ leaves for the raider with the highest bid. In case of a tie, he chooses $R_{1}$ or $R_{2}$ with equal probability. For the sake of simplicity, I assume that $A$ cannot contract with the raiders in period two without having contracted with $F$ in the first period. A possible interpretation of this assumption is that $F$ provides some exclusive "on the job training" to the agent in period one, which is indispensable for performing the second-period task. $^{18}$

Payoffs. The payoff to the agent is

$$
U\left(t_{1}, t_{2}, e\right)=u\left(t_{1}, t_{2}\right)-\psi(e)
$$

where $t_{\tau}$ is the net transfer received by $A$ in period $\tau, \tau=1,2$. Thus, $t_{1} \equiv w_{1}$ and $t_{2}=\max \left\{w_{2}, b_{1}+s, b_{2}+s\right\}$. Let $u$ be strictly increasing and concave in both arguments, $\psi(1)=\psi$ and $\psi(0)=0$. The reservation payoff for $A$ is normalized to 0 .

The firm's payoff $\Pi$ is the sum of its profits in the two periods; i.e., $\Pi=\pi_{1}+$ $\pi_{2}$ where $\pi_{1}=\left(y_{1}-w_{1}\right)$, and $\pi_{2}=\left(y_{2}-w_{2}\right)$ if $A$ works for the firm and $(-s)$ otherwise.

I assume that it is always optimal for $F$ to induce $e=1$. This assumption, along with the fact that $e \in\{0,1\}$, rules out the possibility of inefficiently high effort provision due to excessive career concerns. ${ }^{19}$

Timing. The timing of the game is as follows:

- At the beginning of period $\mathbf{1}, F$ offers a contract, $\phi_{F}$, to the agent. $\phi_{F}$ specifies output contingent payoff in both periods and a disclosure policy. If $A$ rejects the contract, all players get their reservation payoff 0 in both periods and the game ends. If $A$ accepts $F$ 's offer, the game continues on to period 1.1.

- At period 1.1, $A$ chooses his effort level, $e \in\{0,1\}$.

- At the end of period 1, the first-period output $\left(y_{1}\right)$ is realized. $F$ pays first-period wages, $w_{1}\left(y_{1}\right)$, and discloses information $x$ to the raiders.

- At period 2, $R_{1}$ and $R_{2}$ bid for the agent after observing the information, $x$, disclosed by $F$.

\footnotetext{
${ }^{17}$ It is important to note that, under a long-term contract, $A$ will not necessarily leave for the highest paying firm. If there is a severance payment enforced by the contract, $A$ will compare the wages net of the severance payment while choosing his employer.

${ }^{18}$ This assumption can easily be relaxed without affecting any of the results. If $A$ can contract with the raiders even without contracting with $F$ at the first place, it only affects $A$ 's outside option in period one. None of the economic effects are altered at the margin.

${ }^{19}$ Disclosure may heighten career concerns at a level where the resulting effort inducement is inefficiently high. To keep the analysis simple, this potential cost of disclosure is ruled out here by the set up of the model.
} 
- At period 2.1, After observing the raiders' bids, $F$ decides whether to match the best offer; i.e., $F$ may announce a second-period wage-severance payment pair $\left(\hat{w}_{2}, \hat{s}\right)$.

- At period 2.2, $A$ chooses his new employer.

- At the end of period 2, the second-period output is realized. $A$ receives payment from his current employer (and severance payments from $F$ if there was a turnover); at this point, the game ends.

Strategies and Equilibrium. This article focuses only on the pure strategies due to their analytical tractability. A pure strategy for $F, \sigma_{F}$, has two components. In the first-period, $F$ chooses a contract, $\phi_{F}$. In the second period, given the tuple (b, $\left.y_{1}\right), F$ offers a revised wage-severance payment $\left(\hat{w}_{2}, \hat{s}\right)$ to $A$. $A$ 's pure strategy, $\sigma_{A}$, also has two components. In period one, $A$ decides whether to accept the contract, $\phi_{F}$, and whether to put in effort if he does decide to accept the offer. In period two, $A$ chooses his employer once he observes the offers from all players. A pure strategy for the raiders is a mapping $b_{i} \in B$ (maps the realized signal $x$ to a wage offer), conditional on $F$ 's choice of $\phi_{F}$.

I use Perfect Bayesian Equilibrium as a solution concept.

The following section discusses the optimal disclosure policy and establishes two benchmark results given the firm's strategies.

\section{BENCHMARK RESULTS: THE OPTIMALITY OF FULL DISCLOSURE}

This section proves two benchmark results that provide a set of conditions under which full disclosure is optimal for $F$, as outlined in the introduction.

The following notations will be useful in establishing these results. Upon receiving signal $x \in X$, the raiders form a belief about the ability of $A$. Let $\mu(a \mid x)$ be the raiders' posterior belief, i.e.,

$$
\mu(a \mid x)=\frac{\sum_{y_{1}} \delta\left(x \mid y_{1}\right) \operatorname{Pr}\left(y_{1} \mid a\right) \operatorname{Pr}(a)}{\sum_{\tilde{a}} \sum_{y_{1}} \delta\left(x \mid y_{1}\right) \operatorname{Pr}\left(y_{1} \mid \tilde{a}\right) \operatorname{Pr}(\tilde{a})} .
$$

As $F$ may hold more information than the raiders about the agent, raiders face a potential adverse selection problem that affects their bids. The program that raider $R_{i}(i=1,2)$ solves under a long-term complete contract is

$$
\max _{b_{i} \in B} \mathbb{E}_{\left(a, y_{1}\right) \mid x}\left(a-b_{i}\right) \mathbb{I}\left\{b_{i}+\hat{s}\left(\mathbf{b}, y_{1}\right) \geq \max b_{j}(x)+\hat{s}\left(\mathbf{b}, y_{1}\right), \hat{w}_{2}\left(\mathbf{b}, y_{1}\right)\right\},
$$

where $\mathbb{I}(\cdot)$ is an indicator function (recall that $\left.y_{2}=a\right)$. Denote $\mathbb{E}\left(a \mid y_{i}\right)=\bar{a}_{i}(i=$ $H, L)$ as the posterior type of the agent. In what follows, the agent's "type" refers to his posterior type unless indicated otherwise. As the raider market is perfectly competitive, in equilibrium, each raider's bid must be equal to the expected productivity of the agent conditional on the realized signal, and the event of winning the bidding competition (given the strategy of $F$ ). If the highest bid is less than $\bar{a}_{H}$, but greater than $\bar{a}_{L}, F$ will match the raider's offer only in the case of a 
high-type agent. If, instead, it exceeds $\bar{a}_{H}, F$ will let the agent leave irrespective of his type. Whenever the expected productivity of $A$ as perceived by the raiders (i.e., $\mathbb{E}(a \mid x)+m)$ is less than the productivity of the high-type (i.e., $\bar{a}_{H}$ ), a bid of $\mathbb{E}(a \mid x)+m$ can only win a low-type agent. Therefore, the raiders will shade their bid below $\mathbb{E}(a \mid x)+m$. This is similar to the winner's curse effect in a common value auction, when bidders may have different information about the value of the object. ${ }^{20}$

To make the analysis interesting, Assumption 1 ensures that the winner's curse is indeed a relevant consideration for the raiders when they place their bids.

Assumption 1. $\bar{a}_{L}+m<\bar{a}_{H}$.

This assumption puts an upper bound on the matching factor, $m$. If $m$ is so large that the productivity of the low-type agent in the raider's firm (i.e., $\bar{a}_{L}+m$ ) is greater than the productivity of the high-type agent in $F$ (i.e., $\bar{a}_{H}$ ), then the winner's curse effect disappears. As $A$ 's expected productivity in the raider's firm is at least $\bar{a}_{L}+m$, if $\bar{a}_{L}+m>\bar{a}_{H}$, there is turnover for both types of agents whenever the raider bids the expected productivity of $A$.

I shall now characterize the raider's bid as a function of the realized signal. Observe that perfect competition in the raider market implies $b_{1}(x)=b_{2}(x)=$ $b(x)$ for all $x \in X$. Under Assumption 1, due to the winner's curse effect, the raiders will bid the expected productivity of the agent only if it is greater than the productivity of the high-type in $F$. Otherwise, the raiders will bid only for the low-type because $F$ will always match the highest bid if $A$ is of the high-type. The following lemma summarizes this argument.

Lemma 1. Under Assumption 1, under both long-term complete contracts and short-term performance contracts, the raider's bid conditional on the signal $x$ is $b_{1}(x)=b_{2}(x)=b(x)$, where

$$
b(x)= \begin{cases}\mathbb{E}(a \mid x)+m & \text { if } \mathbb{E}(a \mid x)+m>\bar{a}_{H} \\ \bar{a}_{L}+m & \text { otherwise. }\end{cases}
$$

There are three salient features of this bidding strategy. First, a raider wins the agent only if the raider's bid is higher than the valuation of the agent inside the incumbent firm. The agent with type $i$ leaves if and only if $b>\bar{a}_{i}, i=L, H$. Thus, the outcome of this bidding game is the same as when the agent and the firm jointly bargain with the raiders, and always make the efficient trading decision given the bids.

Second, whenever the expected productivity of $A$ in a raider's firm is less than $\bar{a}_{H}$, the raider bids the lowest valuation, $\bar{a}_{L}+m$. A raider's bid as a function of expected productivity of the agent is not continuous at the point $\bar{a}_{H}$, and hence, it is not a convex function. There are further implications of such nonconvexity that I will discuss at the end of this section.

${ }^{20}$ See McAfee and McMillan (1987). 
Third, both short-term and long-term contracts lead to the same bidding function and ex post employment of $A$. Here a long-term contract does not create any barrier to entry (see Aghion and Bolton, 1987, and Spier and Whinston, 1995, on the role of long-term contracts as barriers to entry). Given that $F$ can increase the severance payment ex post, promising a high second-period wage ex ante has no effect on who $A$ ultimately works for.

Let $X(\delta)=\{x \mid \delta(x \mid y)>0$ for some $y \in Y\}$, i.e., the set of signals that are used in the equilibrium with positive probabilities. Define information disclosure as follows:

Definition 1. A contract, $\phi_{F}$, is said to disclose information iff there exist two distinct signals, $x_{l}, x_{k} \in X(\delta)$, such that $\mu\left(\bar{a} \mid x_{l}\right) \neq \mu\left(\bar{a} \mid x_{k}\right)$.

Let $\mathbb{E}_{\left(x, y_{1}\right)}\left[u\left(t_{1}, t_{2}\right) \mid \sigma_{F}, e, \tilde{e}\right]-\psi(e)$ be $A$ 's expected utility when he puts in an effort, $e$, and the outside market believes the effort level to be $\tilde{e}$ (given the strategy of $F$ ). The equilibrium strategy of $F$ must maximize the expected profit from the two periods conditional on $A$ accepting the contract (individual rationality), and having incentives to put in a high effort (incentive compatibility). Hence the optimal contract must solve the following program for $F$ :

$$
\mathcal{P}\left\{\begin{array}{cc}
\max _{\sigma_{F}} & \mathbb{E}_{y_{1}} \pi_{1}+\mathbb{E}_{\left(y_{2}, x\right)} \pi_{2} \\
\text { s.t. } & \mathbb{E}_{\left(x, y_{1}\right)}\left[u\left(t_{1}, t_{2}\right) \mid \sigma_{F}, e=1, \tilde{e}=1\right]-\psi \\
& \geq \mathbb{E}_{\left(x, y_{1}\right)}\left[u\left(t_{1}, t_{2}\right) \mid \sigma_{F}, e=0, \tilde{e}=1\right] \\
& \mathbb{E}_{\left(x, y_{1}\right)}\left[u\left(t_{1}, t_{2}\right) \mid \sigma_{F}, e=1, \tilde{e}=1\right]-\psi \geq 0 .
\end{array}\right.
$$

I define full transparency (or full disclosure) as follows:

Definition 2. $F$ is said to be fully transparent if the optimal contract involves a disclosure policy $\delta$ that unambiguously discloses the information on $y_{1}$, i.e., $\exists$ two signals $x_{L}, x_{H} \in X(\delta)$ such that:

$$
\delta\left(x_{H} \mid y_{H}\right)=\delta\left(x_{L} \mid y_{L}\right)=1, \quad \text { with } x_{H} \neq x_{L} .
$$

The benchmark results of this article provide a set of conditions under which full transparency is the optimal disclosure policy. The first benchmark result considers the case where $F$ can use long-term complete contracts.

PROPOSITION 1. If $F$ can use long-term complete contracts and the raider's market is perfectly competitive, then full transparency is optimal.

The intuition behind this result is the following. By assumption, $A$ is more productive with the raiders. Hence, social surplus is maximized when $A$ leaves for the raiding firm irrespective of his type. With partial disclosure, there is a positive probability that $F$ will retain the high-type agent. This leads to an inefficient level of turnover. Full disclosure ensures the maximum possible matching surplus in the raiding game. It also increases the career concern-based incentives of the agent. As the raider's market is perfectly competitive, $A$ is offered the entire matching surplus, which $F$ can appropriate up front. 
But if $A$ is risk averse, then full disclosure may have an additional cost. When $F$ moves from partial to full disclosure, $A$ faces higher human capital risk. As his second-period wage depends on the realized signal, the spread of second-period wages increases with full disclosure. The firm may need to pay a high risk premium to the agent to ensure that he accepts the contract. This additional premium, in turn, may more than offset the gains from matching, and may make full disclosure a suboptimal strategy. However, with a long-term complete contract the firm can undo the large fluctuations in the agent's period-two payoff induced by disclosure. By choosing severance payments that allow $A$ to obtain exactly the same net transfer as with the initial partial disclosure policy for every output-signal realization, $F$ can shield $A$ from such human capital risk and maintain the same incentives. Hence, if $F$ can use a long-term complete contract, she can resort to full transparency to appropriate maximum gains from matching.

The main purpose of Proposition 1 is to highlight the key economic rationale behind full disclosure in a general framework. In reality, however, long-term contracts are often not feasible, and the use of severance payments (positive and negative) is not very common. Thus, from an applied point of view, one may be more interested in the case of short-term contracts. It turns out that the intuition for Proposition 1 can be applied to the case of short-term contracts, which a firm might use when long-term complete contracts are no longer feasible. In my second benchmark result, I show that, under certain conditions, a short-term performance contract with full transparency can implement the same outcome of an optimal long-term complete contract. Thus, without loss of optimality, $F$ can restrict itself to the class of short-term performance contracts with full transparency if these conditions are satisfied.

Proposition 2. An optimal short-term performance contract induces full disclosure if all of the following conditions hold: (i) A is risk neutral, (ii) A does not face any liquidity constraint, and (iii) the raider market is perfectly competitive.

The intuition behind this result is the same as in Proposition 1; i.e., greater transparency leads to the full realization of gains from matching. In the context of short-term performance contracts, there are two additional considerations, which are absent when long-term complete contracts are feasible. First, a short-term performance contract cannot insure the agent from the human capital risk. Hence, the risk neutrality condition is introduced. Second, to appropriate the gains from trade in a short-term contract, $F$ must adjust $A$ 's wages in the first period. This may require a negative wage payment in period one. If $A$ faces a liquidity constraint, his net transfer in each period has to be nonnegative, ruling out any negative wage payments. This observation justifies the "no liquidity constraint" assumption.

Three issues are worth noting in the context of these two results. First, recall that this no-liquidity-constraint condition was not invoked in the context of long-term complete contracts. When long-term complete contracts are feasible, $F$ can adjust $A$ 's severance payment in period two to appropriate the gains from matching. However, in the second period, $A$ also earns wages from his new employer. He can accommodate a negative severance payment with these wages. 
Second, both of these benchmark results suggest that under the conditions mentioned, the joint surplus between the firm and the agent is maximized through full disclosure. Therefore these results are robust to alternative assumptions about the bargaining between the firm and the agent (note that in the current specification, the firm keeps all the gains from matching and the agent's payoff is always equal to his outside option. i.e., his (IR) constraint is always binding). I will revisit this issue in Section 6.

Finally, the moral hazard problem associated with the unobservability of effort plays no role in the basic intuition behind the full disclosure results. ${ }^{21}$ Under the conditions invoked in the results above, the explicit pay-per-performance contracts and the implicit career concerns incentives are strategic substitutes. Moreover, the explicit contracts can completely undo the impact of full disclosure on career concerns incentive. Therefore, the optimal disclosure policy of the firm is simply the one that maximizes the matching gains, and its impact on incentives is controlled through the pay-per-performance contracts.

The conditions invoked in Propositions 1 and 2 are sufficient for full transparency. They are also "almost" necessary; by relaxing any of these conditions, one can find preferences for the agent and suitable parameters of the model where full disclosure is no longer optimal. The following section provides a characterization of the optimal disclosure policy when the conditions of the benchmark propositions are relaxed. ${ }^{22}$

\section{PARTIAL DISCLOSURE AS THE OPTIMAL POLICY}

This section shows that full transparency may not be the optimal disclosure policy in the absence of any of the three conditions invoked in the benchmark results. In the following subsections, I shall examine these conditions one at a time and characterize the optimal disclosure policy.

5.1. Raider with Monopsony Power. Suppose that there is only one raider who bids for the agent. Since the raider now enjoys monopsony power, the raider's bid in equilibrium does not reflect the true productivity of the agent in the raider's firm. The bidding strategy of the monopsonistic raider is

$$
b(x)= \begin{cases}\bar{a}_{H} & \text { if } \mathbb{E}(a \mid x)>\bar{a}_{H}-P_{1} m \\ \bar{a}_{L} & \text { otherwise }\end{cases}
$$

(Recall that $P_{1}$ is the probability that the agent is of high type.) The argument is again based on the adverse selection problem. All bids in the interval $\left(\bar{a}_{L}, \bar{a}_{H}\right)$ are

\footnotetext{
${ }^{21}$ In fact, the arguments for full disclosure continues to hold if one assumes that the effort is observable. However, as I will discuss in the next section, moral hazard can play an important role in situations where full disclosure is suboptimal.

${ }^{22}$ As a related question, one may also ask whether the firm's profit monotonically increases with the quality of the disclosed information. It does not. This is due to the nonconvexity of the bid function. See Mukherjee (2005a, 2005b) for a complete treatment of this issue.
} 
dominated by the bid $b=\bar{a}_{L}$, since they can only win the low-type agent. With a bid equal to $\bar{a}_{H}$, the raider wins both types; thus, by paying more than $\bar{a}_{H}$ the raider is necessarily overbidding. Hence, the raider will bid $\bar{a}_{H}$ if the expected profit from such a bid is greater than the profit associated with the bid $\bar{a}_{L}$. Now, $\left(1-P_{1}\right)$ is the probability that the agent is of a low-type. By bidding $\bar{a}_{L}$, the raider wins the lowtype agent and gains $m$ on him. On the other hand, by bidding $\bar{a}_{H}$, his expected profit is $\mathbb{E}(a \mid x)+m-\bar{a}_{H}$. Hence, the raider will bid $\bar{a}_{H}$ if $\mathbb{E}(a \mid x)+m-\bar{a}_{H}>$ $\left(1-P_{1}\right) m$.

In this scenario, without loss of generality, $F$ needs to disclose only two signals, $x_{H}$ and $x_{L}$, such that $b\left(x_{H}\right)=\bar{a}_{H}$ and $b\left(x_{L}\right)=\bar{a}_{L} \cdot{ }^{23}$ A disclosure policy, therefore, can be characterized by a tuple $\delta=\left(\alpha_{L}, \alpha_{H}\right)$, where $\alpha_{i}=\operatorname{Pr}\left(x_{H} \mid y_{i}\right), i=L, H$. Let $\alpha_{i}^{*}$ be the corresponding equilibrium value. With full transparency, as before, gains from matching are maximized, but the raider appropriates them entirely. In this case, the incumbent firm can appropriate an informational rent by suitably pooling the low-type agent with the high-type. Proposition 3 characterizes the optimal disclosure policy in this setting. ${ }^{24}$

Proposition 3. If the raider is a monopsonist, both short and long-term optimal contracts induce no information disclosure if $\mathbb{E}(a)>\bar{a}_{H}-P_{1} m$. Otherwise, the optimal disclosure policy is of the form $\alpha_{H}^{*}=1$ and $\alpha_{L}^{*}>0$, where $\left(\alpha_{H}^{*}=1, \alpha_{L}^{*}\right)$ solves $\mathbb{E}\left(a \mid x_{H}\right)=\bar{a}_{H}-P_{1} m$.

Proposition 3 indicates that the optimal partial disclosure policy is of the form (arrows represent the pattern of signaling):

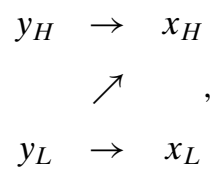

where the low-type is sometimes traded as a high-type agent. This result relies on a simple intuition. $F$ prefers to induce the highest bid from the raiders for all agent types, without distorting the efficient turnover rate. By doing so, $F$ can appropriate the maximum surplus from $A$. If $\mathbb{E}(a)>\bar{a}_{H}-P_{1} m$, then, with no disclosure, the raider will bid $\bar{a}_{H}$-the highest bid that can arise in any equilibrium. In contrast, if $\mathbb{E}(a) \leq \bar{a}_{H}-P_{1} m$, no disclosure leads to a low bid $\left(\bar{a}_{L}\right)$ for all types of agents. $F$ can increase the bid with a positive probability by reporting $x_{H}$ when $y_{1}=y_{H}$. However, full disclosure is not optimal either. $F$ can pool a low-type agent with the one of high type exactly up to the level where the high-type agent still receives a high offer of $\bar{a}_{H}$ (note that the extent of pooling depends on, among other things,

\footnotetext{
${ }^{23}$ To understand the reason, consider any set of signals $X$. Let $X_{L} \subseteq X$ and $X_{H}=X \backslash X_{L}$ be such that $b(x)=\bar{a}_{i}, \forall x \in X_{i}, i=L, H$. Without loss of generality, one can replace all the elements in $X_{L}\left(X_{H}\right)$ with one signal $x_{L}\left(x_{H}\right)$ that is used with the aggregate probability of initially using signals in $X_{L}\left(X_{H}\right)$, given $y_{1}$.

${ }^{24}$ For the sake of brevity, when stating the propositions in this section, I will only mention the condition that is relaxed. The other two conditions are assumed to be in place unless mentioned otherwise.
} 
the proportion of high-type agents $P_{1}$ ). Thus, $F$ may also report $x_{H}$ with a positive probability when $y_{1}=y_{L}$, and can ensure a bid of $\bar{a}_{H}$ even for the low-type agent.

Calzolari and Pavan (2006) derive a similar result in the context of sequential contracting. They show that the extent of information disclosure between upstream and downstream principals depends on, among other things, how favorable the prior belief of the downstream principal is about the agent, when no information is disclosed.

Proposition 3 implies that if there is monopsony in the raider market, a larger matching gain reduces the extent of information disclosure. The following comparative statics result states this observation.

Corollary 1. If $\mathbb{E}(a) \leq \bar{a}_{H}-P_{1} m$, then $\partial \alpha_{L}^{*} / \partial m>0$ under both long-and short-term contracts.

Intuitively speaking, with a high $m$ the raider is more likely to bid a high value, since the gains from matching outweigh the adverse selection cost (raiding a lowtype agent whereas paying for the high-type). Hence, a greater degree of pooling will not distort the turnover rate.

Proposition 3 also highlights another important comparative statics result: Transparency is more likely to be the optimum, as the raider market gets more competitive. This observation links the agent's bargaining power with the firm's optimal disclosure policy. When the raider market is perfectly competitive, the entire bargaining power lies with the agent. The benchmark results suggest that in this case, full disclosure is optimal. However, if the bargaining positions are reversed-when the raider has the entire bargaining power-little or no disclosure is expected. ${ }^{25}$

Liquidity Constraints on the Agent. This subsection discusses the role of "no liquidity constraint" condition invoked in the benchmark result. I continue to assume that the raider market is competitive and $A$ is risk neutral, but relax the "no liquidity constraint" condition. Suppose $A$ is liquidity constrained such that his net transfer in each period must be nonnegative; i.e.,

$$
t_{\tau} \geq 0, \quad \tau=1,2
$$

Proposition 2 shows that "no liquidity constraint on $A$ " is one of the three conditions under which the optimal short-term performance contract induces full transparency. To understand why this condition is useful, consider any feasible solution to the optimal contracting problem where disclosure is partial. In this case, gains from matching are not fully realized. On the other hand, under partial disclosure, $F$ may retain a high-type agent at the wage of a low-type agent and earn an informational rent. When $F$ moves from partial disclosure to full transparency, if she can adjust the first-period wages of $A$, the gain from efficient matching outweighs the loss of informational rent. However, this adjustment may require

\footnotetext{
25 This result can be extended to a more general setting where both the agent and the raider have partial bargaining power.
} 
a negative first-period wage for $A .{ }^{26}$ If $A$ faces a liquidity constraint, such wage adjustments may not be feasible. In this environment, the informational rent that $F$ can earn in a partial disclosure policy can be greater than the gains from efficient matching that $F$ can appropriate up front.

To see this, consider a short-term performance contract where period-one wages are set at zero and the disclosure policy is fully transparent. Let both (IC) and $(I R)$ be slack under this contract; i.e.,

$$
\left(P_{1}-P_{0}\right)\left(\bar{a}_{H}-\bar{a}_{L}\right)>\psi \quad(I C), \quad \text { and } \quad \mathbb{E}(a)+m>\psi \quad(I R) .
$$

Therefore, this contract is a feasible solution to the optimal contracting problem $\mathcal{P}$.

Let $X=\left\{x_{L}, x_{H}\right\}$, and, as before, denote $\alpha_{i}=\operatorname{Pr}\left(x_{H} \mid y_{i}\right), i=L, H$. Recall that under full disclosure, $b\left(x_{i}\right)=\bar{a}_{i}+m, i=L, H$, and there is turnover for both types. With the liquidity constraint in place, under full disclosure $F$ will set $w_{1}\left(y_{L}\right)=w_{1}\left(y_{H}\right)=0$, and its profit will be $\mathbb{E} y_{1}$.

Suppose that $F$ pools the high-type agent with the low-type with a positive probability, i.e., $\alpha_{H}<1$. The disclosure policy then takes on the following form (arrows represent the pattern of signaling):

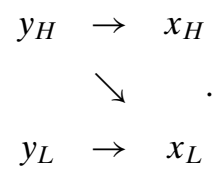

Let $\left(1-\alpha_{H}\right)$ be sufficiently small such that $b\left(x_{L}\right)=\bar{a}_{L}+m$, and both (IC) and $(I R)$ are still satisfied. $F$ now enjoys not only a first-period's profit, $\mathbb{E} y_{1}$, but also a profit in the second period that equals $P_{1}\left(1-\alpha_{H}\right)\left(\bar{a}_{H}-\left(\bar{a}_{L}+m\right)\right)$. The latter arises from the possibility of retaining the high-type agent at the market wage of a low-type agent.

In fact, liquidity constraint matters only when (5) holds.

Proposition 4. Suppose A is liquidity constrained. The optimal short-term contract induces partial disclosure if and only if condition (5) is satisfied.

The "if" part has already been argued above. I shall now elaborate on the "only if" part. Proposition 4 suggests that when the first-period wages are set to zero, if full transparency is not a feasible solution to the optimal contracting problem (i.e., if either $(I C)$ or $(I R)$ in $\mathcal{P}$ is violated), the optimal short-term contract induces full transparency even if $A$ is liquidity constrained. In other words, "no liquidity constraint" is a necessary condition for full transparency only if the career concern incentive is strong (i.e., $\left(\bar{a}_{H}-\bar{a}_{L}\right)$ is large), and the raider's prior expectation of $A$ 's productivity is sufficiently high (i.e., $\mathbb{E}(a)+m$ is large).

\footnotetext{
${ }^{26}$ Recall that, under a short-term performance contract, $F$ has no commitments on $A$ 's secondperiod wages and severance payments.
} 
The intuition behind this result is the following. If condition (5) is violated, then one of the following cases must be true.

$$
\text { (i) }\left(P_{1}-P_{0}\right)\left(\bar{a}_{H}-\bar{a}_{L}\right) \leq \psi \text { or (ii) } \mathbb{E}(a)+m \leq \psi \text {. }
$$

Thus, any partial disclosure contract that is a feasible solution to $\mathcal{P}$ must involve a strictly positive wage payment in period one. But then, $F$ can reduce the expected wage payment by deviating to a full disclosure contract. Observe that full disclosure relaxes both $(I C)$ and $(I R)$ constraints for any given wage payments in period one. The $(I C)$ constraint is relaxed due to stronger career concerns under full transparency. The $(I R)$ constraint is relaxed since full transparency maximizes matching gains, and the entire matching gain is offered to $A$. Since both $(I C)$ and $(I R)$ constraints are now relaxed, and the initial solution involves positive wage payments, $F$ can reduce its expected wage payments without violating any constraints. Therefore, a partial disclosure contract cannot be optimal.

Proposition 4 is also helpful in characterizing the optimal disclosure policy. First, observe that in this setting, similar to the case in Section 5.1, one can restrict attention to a binary signal space $X=\left\{x_{L}, x_{H}\right\}$, without any loss of generality. ${ }^{27}$ Using this fact, Proposition 5 reports the optimal disclosure policy.

Proposition 5. Full disclosure is optimal if and only if condition (5) is violated. Otherwise, the optimal disclosure policy is of the form $\left(\alpha_{H}^{*}, \alpha_{L}=0\right)$, where $\alpha_{H}^{*}<$ 1 , and either (IC) or (IR) (or both) binds. Moreover, $\alpha_{H}^{*}$ is increasing in $\psi$.

The observation on the optimality of full disclosure directly follows from Proposition 4. In addition, Proposition 5 suggests that the partial disclosure policy discussed at the beginning of this subsection is indeed optimal. Since the firm cannot extract any matching gains when the liquidity constraints are binding, it is optimal to maximize profits from retention, subject to the $(I C)$ and $(I R)$ constraints. This is achieved by pooling the high-type agent with the low-type.

Proposition 5 also suggests an interesting comparative statics result. The degree of pooling between the high- and low-type agents is decreasing in the cost of effort $(\psi)$. As $\psi$ increases, the $(I C)$ constraint gets tighter. Thus, $F$ must ensure stronger career concerns incentives to induce effort. Consequently, the extent of pooling across types decreases.

It is also interesting to note that under liquidity constraints, a higher $m$ can induce $F$ to move from full disclosure to partial disclosure. This observation follows from the fact that the condition (5) is more likely to hold with higher $m$. Since one of the benefits of transparency is that it maximizes the matching gains available to $F$ for up front extraction, it may seem counterintuitive that higher matching gains may reduce transparency. However, in this setting, partial disclosure is optimal only if the liquidity constraints are binding for all types. Thus, the extraction of

\footnotetext{
${ }^{27}$ Consider any contract with an arbitrary set $X$. Let $X_{L} \subseteq X$ and $X_{H}=X \backslash X_{L}$ be such that $b(x)=\bar{a}_{L}+m \forall x \in X_{L}, b(x)>\bar{a}_{H} \forall x \in X_{H}$. Because $A$ is risk neutral, without loss of generality, one can replace all the elements in $X_{L}\left(X_{H}\right)$ with one signal $x_{L}\left(x_{H}\right)$ that is used with the aggregate probability of initially using signals in $X_{L}\left(X_{H}\right)$, given $y_{1}$.
} 
matching gains is no longer feasible to $F$, and the optimal disclosure policy is driven by the retention profits instead of the matching gains.

5.2. Risk Averse Agent. This subsection relaxes the risk neutrality condition invoked in the benchmark result under short-term contracts. Disclosure of performance exposes $A$ to a human capital risk, because $A$ 's period-two payoff may fluctuate with his period-one performance. I have already argued that under long-term complete contracts, $F$ can fully insure $A$ from the human capital risk. In contrast, under short-term performance contracts, $F$ can only partially countervail the human capital risk by appropriately adjusting the first-period wages, but may not be able to eliminate the risk completely. Thus, when $A$ is risk averse, $F$ must pay an additional risk premium if she disclosures $A$ 's performance information. The risk premium that $F$ must pay to $A$ under full transparency may outweigh the associated gains from trade. Therefore, full transparency can be suboptimal.

As explained earlier, partial disclosure results in inefficient matching due to the adverse selection problem. Thus, the optimal disclosure policy under a short-term contract trades off the gains from efficient matching with the cost of the additional risk premium.

A formal analysis of this trade-off in the general framework may not be easily tractable. The key complication lies in the fact that number of signals to be used in the optimal contract (i.e., the cardinality of $X$ ) is endogenous. And, when $A$ is risk averse, one cannot restrict the cardinality of $X$ to a tractable number without any loss of generality. Therefore, to keep the exposition simple, I will consider a special case where $X=\left\{x_{L}, x_{H}\right\}$. As before, a disclosure policy can be characterized by a tuple $\delta=\left(\alpha_{H}, \alpha_{L}\right)$ where $\alpha_{i}=\operatorname{Pr}\left(x_{H} \mid y_{i}\right), i=L, H$. Although the optimal disclosure policy derived under this setting may not be the optimal disclosure policy for any general set $X$, the analysis is helpful in delineating the role of key parameters in a firm's disclosure decision.

Let the agent's utility be of the form $U\left(t_{1}, t_{2}\right)=u_{1}\left(t_{1}\right)+u_{2}\left(t_{2}\right)-\psi(e)$, and denote $w_{i}=w_{1}\left(y_{i}\right), i=L, H$. Also assume that $\left(P_{1}-P_{0}\right)\left(u_{2}\left(\bar{a}_{H}\right)-u_{2}\left(\bar{a}_{L}\right)\right)<\psi$, so that $(I C)$ and $(I R)$ will both bind at the optimum. The optimal short-term performance contract solves the following program:

$$
\mathcal{P}^{\prime}\left\{\begin{array}{c}
\max _{\alpha_{H}, \alpha_{L}, w_{H}, w_{L}} \mathbb{E}_{y_{1}}\left(y_{1}-w_{1}\left(y_{1}\right)\right)+P_{1}\left(1-\alpha_{H}\right)\left(\bar{a}_{H}-\left(\bar{a}_{L}+m\right)\right) \\
\text { s.t. } \quad\left(P_{1}-P_{0}\right)\left[\left(u_{1}\left(w_{H}\right)+\mathbb{E}_{b}\left(u_{2}(b) \mid y_{H}\right)\right)\right. \\
\left.-\left(u_{1}\left(w_{L}\right)+\mathbb{E}_{b}\left(u_{2}(b) \mid y_{L}\right)\right)\right]=\psi, \\
P_{1}\left(u_{1}\left(w_{H}\right)+\mathbb{E}_{b}\left(u_{2}(b) \mid y_{H}\right)\right) \\
+\left(1-P_{1}\right)\left(u_{1}\left(w_{L}\right)+\mathbb{E}_{b}\left(u_{2}(b) \mid y_{H}\right)\right)=\psi .
\end{array}\right.
$$

$\mathbb{E}_{b}\left(u_{2}(b) \mid y_{i}\right)$ is the second-period expected utility of $A$ when $y_{1}=y_{i}$, i.e., $\alpha_{i} u_{2}\left(b_{H}\right)+\left(1-\alpha_{i}\right) u_{2}\left(b_{L}\right), i=L, H$. $)$ The optimal disclosure policy is determined by the interaction of two effects: human capital risk and matching efficiency. 
Though I have discussed these two effects in the context of the benchmark results, these effects involve additional complexities under short-term contracts when $A$ is risk averse. Therefore, for expositional clarity, I will first discuss each of the two effects in isolation, and then study the interaction between the two.

Human capital risk: Consider a simple case where effort is observable. This case rules out the moral hazard problem, and the only risk that $A$ is still exposed to is the human capital risk. For any given disclosure policy, the optimal wages are given by the following equation:

$$
w_{H}^{*}=w_{L}^{*}=w^{*}=u_{1}^{-1}\left(\psi-\mathbb{E}_{b} u_{2}(b)\right) .
$$

Equation (6) suggests that the higher is $A$ 's expected payoff in period two $\left(\mathbb{E}_{b} u_{2}(b)\right)$, the lower is the expected wage payment $\left(w^{*}\right)$ for $F$. Full transparency results in the highest spread in the raiders' bid. Because $u_{2}$ is concave, a partial disclosure policy that implies the same expected bid as under full transparency (i.e., $\mathbb{E}(a)+m)$ but results in a smaller spread of bids necessarily decreases the expected wage payment. Therefore, partial disclosure can enhance $F$ 's profit by reducing the required human capital risk premium. The more risk averse the worker is, the more incentive the firm has to filter information to save on the risk premium.

Next, consider the general case of unobservable effort that leads to a moral hazard problem. In this case, the human capital risk plays an additional role that can be beneficial to the firm. The human capital risk offers a career concerns incentives that can lessen the classic tension between incentive and insurance associated with the moral hazard problem. To see this, observe that the optimal wages $\left(w_{L}^{*}, w_{H}^{*}\right)$ that solve $\mathcal{P}^{\prime}$ for a given disclosure policy are

$$
\begin{aligned}
& w_{L}^{*}=u_{1}^{-1}\left(\psi-\frac{P_{1} \psi}{\Delta P}-\mathbb{E}_{b}\left(u_{2}(b) \mid y_{L}\right)\right) \\
& w_{H}^{*}=u_{1}^{-1}\left(\psi+\frac{\left(1-P_{1}\right) \psi}{\Delta P}-\mathbb{E}_{b}\left(u_{2}(b) \mid y_{H}\right)\right) .
\end{aligned}
$$

The spread between $\mathbb{E}_{b}\left(u_{2}(b) \mid y_{L}\right)$ and $\mathbb{E}_{b}\left(u_{2}(b) \mid y_{H}\right)$ represents the career concerns incentive. A move from a partial disclosure policy to full disclosure enhances the career concerns incentives by increasing the spread between $\mathbb{E}_{b}\left(u_{2}(b) \mid y_{L}\right)$ and $\mathbb{E}_{b}\left(u_{2}(b) \mid y_{H}\right)$. It allows $F$ to weaken the explicit incentives. ${ }^{28}$ As a result, the spread between the explicit wages $w_{H}^{*}$ and $w_{L}^{*}$ decreases. Because $u_{1}^{-1}$ is convex, a smaller spread in period-one wages may result into a lower expected wage payment.

The potential savings in wage payments originate from an intertemporal substitution of risk. The interaction between the explicit incentive contracts and

\footnotetext{
${ }^{28}$ Equation (7) suggests that in this model, career concerns incentives are a strategic substitute for the explicit incentives. The stronger are the career concerns incentives, the weaker are the explicit incentives under the optimal contract.
} 
the career concerns incentives allows $F$ to spread the work incentive across the two periods. In the process, $F$ offers a better income insurance to $A$ in period one, but at the cost of an additional human capital risk in period two. Depending on the parameter values and the preference of the agent, such an intertemporal substitution of risk may reduce the aggregate risk premium that $F$ must pay to $A$. The higher is the risk aversion in period one (relative to period two), the more $F$ can save in aggregate risk premium by moving toward full disclosure.

Matching efficiency: A partial disclosure policy may lead to inefficient turnover due to the adverse selection problem. Inefficient turnover has two implications: (i) it reduces the total matching gains that $F$ can extract from $A$, and (ii) it allows $F$ to retain a high-type agent at the wage of a low-type and earn retention profit. The benchmark results show that if $F$ can extract the entire matching gains from $A$ dollar for dollar, then $F$ profits from efficient turnover ensured by full transparency. The gains from matching efficiency outweigh the forgone retention profits.

This may not be the case under short-run contracts if $A$ is risk averse. The key issue is that if $A$ 's payoff increases in period two, $F$ can only extract it by lowering $A$ 's wage in period one. When $A$ is risk averse (more generally, when $A$ 's utility function is not linear), a dollar increase in $A$ 's period-two wage may not compensate for a dollar decrease in his period period-one wage. That is, if the raiders' bid for $A$ increases in period two, $F$ may not be able to extract the incremental bid dollar for dollar by lowering $A$ 's wage in period one. Thus, $F$ might not be able to reap the entire benefit of the matching gains. Instead, $F$ might find it more profitable to take advantage of the adverse selection problem and retain a high-type agent at the cost of a low-type one. The loss of profits due to matching inefficiency can be more than compensated by the gains from retention. ${ }^{29}$ As before, the form of the function $u$ and the associated parameter values determine which effect will be the dominant one.

I will now consider the interaction between the two effects. In the light of the discussion above, it is useful to assume a specific functional form of $u$. This will allow us to parameterize the degree of risk aversion, and will facilitate our understanding of some comparative statics results. Suppose $A$ has CARA utility function, i.e., $u_{1}(x)=u_{2}(x)=V-e^{-r x}, r>0$. This functional form represents constant absolute risk aversion, captured by parameter $r$. The associated inverse function is $h(u)=-\frac{1}{r} \ln (V-u)$. Using this functional form and the optimal wage Equation (7), program $\mathcal{P}^{\prime}$ can be rewritten as (I drop the terms that do not involve $\alpha_{H}$ or $\left.\alpha_{L}\right)$

\footnotetext{
${ }^{29}$ To see this more clearly, consider the simple case of observable effort. Suppose the firm moves from a partial disclosure policy where $\alpha_{H}<1$ to a full disclosure policy (i.e., it increases $\alpha_{H}$ ). The loss of retention gains is $P_{1}\left(\bar{a}_{H}-\left(\bar{a}_{L}+m\right)\right)$. But the gains from the matching efficiency, reflected by a lower period-one expected wage payment, is $-u_{1}^{-1 \prime}\left(\psi-\mathbb{E}_{b} u_{2}(b)\right) \mathbb{E}_{b} \partial u_{2}(b) / \partial \alpha_{H}$ (see Equation (6)). When $u_{1}$ and $u_{2}$ are identical linear functions, the gain necessarily outweighs the loss (this is shown in the benchmark results). This need not be the case if $u_{1}$ and $u_{2}$ are concave.
} 


$$
\begin{aligned}
\max _{\alpha_{H}, \alpha_{L} \in[0,1]} \tilde{\Pi}=\frac{1}{r} & {\left[P_{1} \ln \left(V-\psi-\frac{\left(1-P_{1}\right) \psi}{\Delta P}+u_{2 H}\right)\right.} \\
& \left.+\left(1-P_{1}\right) \ln \left(V-\psi+\frac{P_{1} \psi}{\Delta P}+u_{2 L}\right)\right] \\
+ & P_{1}\left(1-\alpha_{H}\right)\left(\bar{a}_{H}-\left(\bar{a}_{L}+m\right)\right) .
\end{aligned}
$$

The following proposition suggests that if $A$ is sufficiently risk averse, partial disclosure can be optimal. ${ }^{30}$

Proposition 6. If $A$ has CARA preference, then partial disclosure is strictly optimal for sufficiently high risk aversion (given the values of all other parameters).

The intuition behind this result is straightforward. With the specific form of the utility function, human capital risk effect intensifies with the degree of risk aversion, but the marginal gains to $F$ from the matching efficiency decrease (relative to the retention profits). Consequently, for $r$ sufficiently high, $F$ opts for partial disclosure to save on risk premium at the cost of forgone matching efficiency. ${ }^{31}$

It is important to note that the trade-off between matching efficiency and risk hinges on the extent to which a short-term contract can mitigate the human capital risk. In fact, when $A$ 's period-one and period-two incomes are perfect substitutes, a short-term contract can completely offset the additional human capital risk. Therefore, in this case, risk neutrality of $A$ is no longer necessary to ensure full transparency. Proposition 7 establishes this observation.

Proposition 7. If $A$ is risk averse, the optimal short-term contract for $F$ induces full transparency if $u\left(t_{1}, t_{2}\right)=u\left(t_{1}+t_{2}\right)$.

When the agent's utility depends on the aggregate net transfer in the two periods, a short-term performance contract can countervail any fluctuation in $t_{2}$ by adjusting $t_{1}$ and keeping the aggregate payoff unchanged. In the process, $F$ can completely insure $A$ from the additional human capital risk associated with full transparency. Similar to the benchmark case, transparency becomes optimal because it maximizes the matching gains that $F$ can fully extract from $A$.

\section{DISCUSSION AND EXTENSIONS}

In this section, I explore the labor market implications of my main results. I also investigate whether they are robust to some of the simplifying assumptions of the model, and how they can be extended to environments where some of these assumptions need not hold.

\footnotetext{
${ }^{30}$ Note that this result does not hinge on the simplifying assumption of binary signal space $\left\{x_{L}\right.$, $\left.x_{H}\right\}$. Indeed, since output is binary, a binary signal space is sufficient in this model to represent full transparency.

31 The discussion on human capital risk and matching efficiency also suggests that the higher the $r$, the less transparent the firm. Similarly, the level of transparency increases with $m$.
} 


\subsection{Labor Market Implications.}

6.1.1. Practical implementation of the disclosure policies. In the discussion of the optimal disclosure policy, I have purposefully considered an abstract signal space for the sake of generality. But how could a firm implement the proposed disclosure policies in real life? Optimal disclosure policy may have severe implications on any strategy of the firm that may influence the visibility of the worker's performance to the outside market (e.g., promotion rules, job design).

Full disclosure may correspond to a direct revelation of the output (I will revisit this issue in Section 6.2.3). It may also correspond to a strategic job design that makes the worker more visible to the potential raiders. As discussed in the HCL America case, sending the workers to the client's site instead of doing projects in-house may ensure full disclosure.

For the partial disclosure policies, first consider the case of a monopsonist raider. In Section 5.1, I argue that the optimal policy requires pooling the low-type agent with the high-type with a suitable probability. This may correspond to a promotion rule, according to which an incompetent worker is sometimes promoted only to lure the raider into bidding a high value for him. This is in contrast with the result shown by Waldman (1984), where promotion is often denied even to a competent worker. He argues that promotion is a signal of high ability, and therefore, raises the market wage of the worker, making retention more costly for the firm. However, a similar argument holds when the agent faces a liquidity constraint. As the optimal disclosure policy may involve mixing the high-type agent with the low-type, such policy may result in too few promotion offers. ${ }^{32}$ The firm can also implement a partial disclosure policy by moderating the frequency with which it reveals the worker's performance measure. For example, in the liquidity constraint case, the firm may opt not to reveal the low-type ever and to reveal the high-type only infrequently so as to facilitate retention gains. Infrequent revelation of information can also shield the agent from the additional human capital risk associated with full disclosure.

6.1.2. Possible justifications for some observed disclosure decisions. The model discussed here is particularly relevant for temporary help supply (THS) firms, and the firms in the service sector industries like software, consulting, etc. Most of the THS firms train their workers in general skills (Autor, 2001), and certify such training to the future employers of their workers. Young workers in these firms often take their employment as an investment in skill acquisition and later leave for a permanent job where the acquired skills are more useful. Consequently, THS firms that offer training can hire workers at wage lower than the wage offered by THS firms that do not offer training.

In software firms, the workers are often required to acquire specific skills to serve their clients. The client firms may provide incentives for specific skill acquisition more efficiently. Mukherjee (2003) shows that, if skill acquisition is perfectly

\footnotetext{
${ }^{32}$ In contrast with Waldman's framework, this article abstracts away from the productive inefficiency that may be associated with too few promotions.
} 
observed by all parties, efficiency is enhanced when implicit incentives through relational contracts are used along with the explicit contracts. A specific skill acquired for a client's job is often not observable to the employer. However, if the worker switches jobs to join the client's firm, she can reward the worker through a relational contract, which increases the worker's productivity through better skill acquisition. Hence, it is more likely that the worker will be a better match for the client. This may explain why the clients are often the raiders in consulting and software firms. Moreover, when the client firm tries to raid workers, it may enjoys a monopsony power, because the firm might be the only one (other than the initial employer) who has observed the worker's productivity for a considerable duration of time. Therefore, my model predicts that these firms will resort to a partial disclosure policy. This is also reflected in the HCL America case.

\subsection{Role of Key Assumptions}

6.2.1. Value of commitment. The firm's ability to commit to a disclosure policy is important for the results presented here. Given the raider's bidding strategy, in the absence of any commitment on disclosure policy, the coalition of the firm and the agent has an ex post incentive to collude and deviate from the proposed disclosure policy. Foreseeing such deviation, the raider will also deviate from the bidding strategy that is discussed above. In other words, if the firm cannot credibly commit to a disclosure policy, the strategies described above are not best responses to each other. The equilibrium strategies of the player where the firm lacks commitment power need not ensure efficient turnover and, hence, may not maximize the joint surplus associated with the turnover. Thus, the firm's ability to commit generates value for the firm.

To see the intuition, note that in absence of any commitment, the raiders' bidding strategy must be a unique bid (instead of a menu contingent on the revealed signal), as otherwise, the firm will always reveal the signal that induces the highest bid. But due to adverse selection, the equilibrium bid must be equal to the value of the lowest-type agent with the raiders. Therefore, in equilibrium the firm may adopt any disclosure policy and the raider's bid is invariant to the firm's disclosure and equal to the productivity of the lowest-type agent. Turnover is inefficient as there is no turnover of the high-type agent.

If one interprets job design as a mechanism to filter information, firms may be able to commit to a particular disclosure policy by implementing a certain job design (e.g., deciding whether to keep professionals in-house or let them work in the client's site, as discussed in the IT firm example). As it may be costly to change the design, the irreversibility of job design (at least in the short run) may allow the firm to credibly commit to a disclosure policy and preclude the possibility of collusion between firm and the agent.

6.2.2. Bargaining between agent and initial employer. I have assumed that the initial employer is a monopsonist and extracts all available surplus from the agent; i.e., the individual rationality constraint (and liquidity constraint, if relevant) of the agent always binds. Would the results change if one assumes a different division 
of surplus between the firm and the agent? In almost all cases, it will not. It is important to note that except in the case of liquidity-constrained agent, the optimal disclosure policy maximizes the joint surplus between the firm and the agent. Therefore, the optimal disclosure policy (except the liquidity constraint case) is robust to any change in the division of surplus that the firm and the agent may agree upon at the beginning of the game.

There are two important implications of this observation. First, absent liquidity constraint, once the parties agree up front on the division of surplus, their ex ante disclosure incentives are aligned. Second, even if one assumes that the initial employer participates in a perfectly competitive labor market (i.e., where all surplus must go to the agent), the optimal disclosure policy will be qualitatively unchanged.

6.2.3. Observability of output and wages. If the output is intrinsically observable to the raiders, the firm has no private information and the question of information disclosure is irrelevant. But what happens if the firm can make output observable at its own discretion? The qualitative nature of all the results is robust to such an assumption. To see the intuition, first consider the benchmark results. By definition, full disclosure is equivalent to revealing output itself. Similarly, as one can interpret "sending no signal" as a distinct signal, the pooling cases considered in partial disclosure results can be replicated by not revealing the output with certain probability conditional on the realized level of output. For example, in the monopsonist raider case the firm may never disclose the output if it is high, and may disclose it only with some probability (i.e., $1-\alpha_{L}^{*}$, as discussed in Section 5.1) if it is low. This observation also suggests that if the firm is restricted to implement the disclosure policy only by manipulating the observability of the agent's output, all of the aforementioned results are qualitatively unchanged.

A related question is what happens if the agent can signal his productivity by credibly revealing his wages? As mentioned previously, except in the case of liquidity-constrained agent, the optimal disclosure policy maximizes the joint surplus between the firm and the agent associated with turnover subject to the bidding strategies of the raiders. Thus, unless the agent is liquidity constrained, he has no incentive to perfectly disclose his type when the firm finds it optimal to filter information. . $^{33,34}$

\footnotetext{
${ }^{33}$ In other words, consider a scenario where the agent can commit to a disclosure policy using period-one wages as signals of productivity. Suppose that $F$ allows the agent to reveal his type for a lump sum transfer payment (i.e., if $F$ sells her "right" to information disclosure to $A$ for a fixed payment). The discussion above suggests that absent any liquidity constraint, $A$ 's disclosure decision will be qualitatively same as that of $F$ (because it maximizes the joint surplus).

${ }^{34}$ One may also ask the following: When the agent cannot commit to any disclosure policy but may credibly reveal his type through his period-one wages, does he have an incentive to interfere with the firm's disclosure policy? Clearly, in the liquidity constraint case, the high type agent has an incentive to reveal his type, since his is being paid a low-type's wage under the firm's disclosure policy. In all other settings, revelation of wage may not help the agent.

To see this, first consider the benchmark cases of full disclosure. When the firm fully discloses the agent's type, trivially, there is no role for additional disclosure of wage/output information. Now, under the monopsonist raider case, a high-type agent always gets the highest wage offer, but the firm also
} 
6.2.4. Ability-dependent matching factor. I have assumed that the gains from matching, $m$, are independent of ability levels and turnover is efficient for all types. Instead, one may assume that the matching factor can be negative or positive depending on the ability level, i.e., $m=m(a)$ and $m(\underline{a})<0<m(\bar{a})$. In the initial model, I argued that turnover might be too low under a partial disclosure policy. In the current scenario, partial disclosure can also lead to too much of turnover. If $m(\underline{a})$ is a sufficiently large negative number compared to $m(\bar{a})$, then $\mathbb{E}\left(m(a) \mid y_{L}\right)<$ $0<\mathbb{E}\left(m(a) \mid y_{H}\right)$. At the first best level of turnover, only the high-type should switch to the raider's firm. The raider's bidding function is

$$
b(x)= \begin{cases}\mathbb{E}(a+m(a) \mid x) & \text { if } \mathbb{E}(a+m(a) \mid x)>\mathbb{E}\left(a \mid y_{H}\right) \\ \mathbb{E}\left(a+m(a) \mid y_{L}\right) & \text { otherwise }\end{cases}
$$

As before, under a partial disclosure policy, following $y_{1}=y_{H}$, turnover can be too low due to the winner's curse effect. On the other hand, following $y_{1}=$ $y_{L}$, turnover can be too high, as for some signals both types may leave for the raider's firm. This observation, again, calls for full transparency to maximize the trading surplus. The benchmark results in this article are therefore robust to such modification (see Mukherjee, 2005a, for a rigorous treatment of this issue).

\section{CONCLUSION}

This article presents a model of sequential contracting in labor markets where, compared to the prospective employers, the initial employer has better information about the agent. When the agent cares about his reputation, and matching between the worker and the firm affects productivity, there is a scope for the initial employer to increase her payoff through strategic information disclosure. The article provides a characterization of the optimal disclosure policy in such an environment.

If the initial employer can write a long-term complete contract, then competition in the raider market ensures full disclosure. When long-term contracts are infeasible, the firm may choose short-term performance contracts with full disclosure when (i) the agent is risk neutral, (ii) the agent faces no liquidity constraint, and (iii) the raider market is perfectly competitive. These sufficient conditions for full disclosure are also "almost" necessary in the sense that if any of them is relaxed, one can find preferences for the worker and the parameter values for which full disclosure is not optimal.

The trade-offs emphasized in this article need not be the sole driver of a firm's disclosure decision. However, the fact that the identified conditions are both

pools the low-type agent with the high-type. Thus, the high-type agent cannot gain by revealing his type. Moreover, the low-type agent can only reduce his offer if he signals his true type. Finally, under risk aversion, the firm may offer insurance by pooling only the low type with the high type. If this is the case, then a low-type agent can reveal his wage/output information only at his own detriment. However, if the optimal disclosure policy pools high-type with the low-type, the high-type agent may reveal his period-one wage ex post to increase his period-two wage. 
sufficient and "almost necessary" makes a strong case for them as determinants of organizational transparency.

\section{APPENDIX: PROOFS OMITTED IN THE TEXT}

Proof of Lemma 1. Observe that $b_{1}(x)=b_{2}(x)$ as raiders compete in their bids to win the agent.

First consider the case of long-term complete contract. I derive the bidding function in following steps.

Step 1. Let $b(x)=b$. Further suppose that the final offer from $F$, upon observing $b$, is $\left(\hat{w}_{2}, \hat{s}\right)$. In any equilibrium $A$ stays with $F$, iff $\hat{w}_{2} \geq b+\hat{s}$, or

$$
\hat{w}_{2}-\hat{s} \geq b \text {. }
$$

Moreover, $F$ prefers to retain the agent with $y_{1}=y_{i}(i=L, H)$ by choosing an appropriate $\left(\hat{w}_{2}, \hat{s}\right)$ pair iff $\bar{a}_{i}-\hat{w}_{2} \geq-\hat{s}$ or

$$
\bar{a}_{i} \geq \hat{w}_{2}-\hat{s} .
$$

Step 2. (A.1) and (A.2) imply that there is turnover with $y_{1}=y_{i}$ if and only if $\bar{a}_{i}<b$.

The proof of the "if" part directly follows from Equations (A.1) and (A.2). When there is no turnover, Equations (A.1) and (A.2) must hold. Together, they imply $\bar{a}_{i} \geq b$. Hence, if $\bar{a}_{i}<b$ then there is turnover.

To prove the "only if" part, I shall argue that if $\bar{a}_{i} \geq b$, then there is no turnover. Let the initial offer be $\left(w_{2}, s\right)$. If $\bar{a}_{i} \geq w_{2}-s \geq b$ then both $F$ and $A$ would prefer to continue the employment relationship leading to no turnover.

When $\bar{a}_{i} \geq b>w_{2}-s, A$ prefers to leave at the current wages whereas $F$ would like to keep him. $F$ would offer $\hat{w}_{2}>w_{2}$ such that $\hat{w}_{2}-s=b$. At the offer $\left(\hat{w}_{2}, s\right), A$ would stay and $F$ would still prefer that to letting him go as $\bar{a}_{i}-\hat{w}_{2} \geq-s$ when $\bar{a}_{i} \geq b$.

Finally, if $w_{2}-s>\bar{a}_{i} \geq b, A$ prefers to stay whereas $F$ makes a loss on him. But it will not be viable for $F$ to make $A$ leave. $A$ leaves only if $F$ raises $s$ to $\hat{s}$ such that $w_{2}-\hat{s}<b$. So it must be the case that $\bar{a}_{i}-w_{2}>-\hat{s}$. Hence $F$ is better off by keeping $A$ than to pay him to leave.

Step 3. Observe that for any $x$, bidding in the interval $\left(\bar{a}_{L}, \bar{a}_{H}\right]$ is dominated by bidding $\bar{a}_{L}+m$. If the raiders are bidding in the interval $\left(\bar{a}_{L}, \bar{a}_{H}\right)$ they are sure to get the low-type agent. If $\bar{a}_{L}<b<\bar{a}_{H}$, by step 2, $F$ will let the low-type agent quit while retaining the high-type agent. Therefore, competition ensures that raider's will bid $\bar{a}_{L}+m$. They are necessarily overbidding if they bid in the interval $\left(\bar{a}_{L}+m, \bar{a}_{H}\right]$, and they will not win the agent if their bid is in the interval $\left(\bar{a}_{L}, \bar{a}_{L}+m\right)$.

Step 4. Bidding in the interval $\left(\bar{a}_{H}, \infty\right)$ ensures that the agent will work for the raiders irrespective of his types (here $\bar{a}_{i}<b$ where $i=H, L$ ). Therefore 
the expected productivity of the agent when the bid is in the interval $\left(\bar{a}_{H}, \infty\right)$ is $\mathbb{E}(a \mid x)+m$. Hence, raiders will bid $\mathbb{E}(a \mid x)+m$ only if $\mathbb{E}(a \mid x)+m>\bar{a}_{H}$.

Combining these observations I get Equation (2).

Next, I consider the case of short-term performance contracts. Recall that a short-term performance contract is a special case of long-term complete contracts where $w_{2}=s=0$. Under the short-term performance contract, in period two, $F$ solves

$$
\max _{\hat{w}_{2} \geq 0} \mathbb{E}_{y_{2} \mid y_{1}}\left(y_{2}-\hat{w}_{2}\right) \mathbb{I}\left\{\hat{w}_{2} \geq \max \left\{b_{1}, b_{2}\right\}\right\}
$$

Hence, $F$ will match the highest bid as long as the bid is less than the type of the agent. So for any $b<\bar{a}_{H}, F$ will match the bid only for the high-type agent. This implies Equation (2) by steps 3 and 4.

Proof of Proposition 1. Step 1. Consider a candidate equilibrium $\mathcal{E}$ associated with the program $\mathcal{P}$. Let $\delta$ be the associated disclosure policy and $\exists x_{k}, x_{l} \in X(\delta)$ such that $0<\delta\left(x_{k} \mid y\right) \delta\left(x_{l} \mid y\right)<1$ for some $y \in\left\{y_{L}, y_{H}\right\}$.

Let $X_{H}=\left\{x \in X(\delta) \mid b(x) \geq \bar{a}_{H}\right\}$, i.e., the set of signals for which the raider's bid is greater than $F$ 's valuation of the highest possible type. Further define $X_{L}=$ $X \backslash X_{H}$. From (2), I claim that $\forall x \in X_{H}$ there is turnover and for $x \in X_{L}$, there is turnover iff $y=y_{L}$. Therefore, the profit to $F$ in $\mathcal{E}$ is

$$
\begin{aligned}
\Pi= & P_{1}\left(y_{H}-\mathbb{E}\left(w_{1} \mid y_{H}\right)\right)+\left(1-P_{1}\right)\left(y_{L}-\mathbb{E}\left(w_{1} \mid y_{L}\right)\right) \\
& +P_{1}\left(-\int_{X_{H}} \hat{s}\left(x, y_{H}\right) \delta\left(x \mid y_{H}\right) d x+\int_{X_{L}}\left(\bar{a}_{H}-\hat{w}_{2}\left(y_{H}, x\right)\right) \delta\left(x \mid y_{H}\right) d x\right) \\
& -\left(1-P_{1}\right) \int_{X} \hat{s}\left(x, y_{L}\right) \delta\left(x \mid y_{L}\right) d x .
\end{aligned}
$$

(Recall that a long-term complete contract allows for randomization in wages in the first period.)

Step 2. Consider another candidate equilibrium $\mathcal{E}^{*}$ defined as follows: Let the associated disclosure policy be fully transparent. In addition, suppose that $F$ also generates another signal $x \in X$ according to the disclosure policy $\delta$. The period-two wages and severance payments of $A,\left(w_{2}^{*}, s^{*}\right)$, are based on the realized $x$ values. Let $w_{1}$ be unchanged from the initial contract and set $w_{2}^{*}=s^{*}=\hat{w}_{2}^{*}=\hat{s}^{*}$ where $\hat{s}^{*}$ is given by the equation

$$
b\left(y_{1}\right)+\hat{s}^{*}\left(x, y_{1}\right)=\max \left\{b(x)+\hat{s}\left(x, y_{1}\right), \hat{w}_{2}\left(x, y_{1}\right)\right\} \forall x \in X \text { and } y_{1} \in Y,
$$

where $b\left(y_{1}\right)=\mathbb{E}\left(a \mid y_{1}\right)+m$, the bid of the raiders when $y_{1}$ is directly revealed under full transparency. By construction, facing this contract $A$ will choose the same effort level and receive the same expected utility as in the initial contract given in $\mathcal{E}$. 
Step 3. Under the new contract, following $y_{1}=y_{i}, F$ 's profit will be

$$
\Pi_{i}^{*}=y_{i}-\mathbb{E}\left(w_{1} \mid y_{i}\right)-\int_{X} \hat{s}^{*}\left(x, y_{i}\right) \delta\left(x \mid y_{i}\right) d x \quad i=L, H
$$

Note that (A.3) implies

$$
\begin{aligned}
\bar{a}_{H} & +m+\int_{X} \hat{s}^{*}\left(x, y_{H}\right) \delta\left(x \mid y_{H}\right) d x \\
& =\int_{X_{H}}\left(b(x)+\hat{s}\left(x, y_{H}\right)\right) \delta\left(x \mid y_{H}\right) d x+\int_{X_{L}} \hat{w}_{2}\left(x, y_{H}\right) \delta\left(x \mid y_{H}\right) d x
\end{aligned}
$$

and

(A.6) $\bar{a}_{L}+m+\int_{X} \hat{s}^{*}\left(x, y_{L}\right) \delta\left(x \mid y_{L}\right) d x=\int_{X}\left(b(x)+\hat{s}\left(x, y_{L}\right)\right) \delta\left(x \mid y_{L}\right) d x$.

It remains to show that $F$ 's profit under the new contract, $\Pi^{*}=P_{1} \Pi_{H}^{*}+\left(1-P_{1}\right)$ $\Pi_{L}^{*} \geq \Pi$.

Step 4. Using (A.5) and (A.6), I claim

$$
\begin{aligned}
\Pi^{*}= & P_{1} \Pi_{H}^{*}+\left(1-P_{1}\right) \Pi_{L}^{*} \\
\geq & P_{1} \Pi_{H}^{*}+\left(1-P_{1}\right) \Pi_{L}^{*}-m \int_{X_{L}} \delta\left(x \mid y_{H}\right) d x \\
= & P_{1}\left(y_{H}-\mathbb{E}\left(w_{1} \mid y_{H}\right)\right)+\left(1-P_{1}\right)\left(y_{L}-\mathbb{E}\left(w_{1} \mid y_{L}\right)\right) \\
& +P_{1}\left[\bar{a}_{H}+m-\int_{X_{H}}\left(b(x)+\hat{s}\left(x, y_{H}\right)\right) \delta\left(x \mid y_{H}\right) d x\right. \\
& \left.\quad+\int_{X_{L}}\left(\bar{a}_{H}-\hat{w}_{2}\left(x, y_{H}\right)\right) \delta\left(x \mid y_{H}\right) d x-\int_{X_{L}}\left(\bar{a}_{H}+m\right) \delta\left(x \mid y_{H}\right) d x\right] \\
& +\left(1-P_{1}\right)\left[\bar{a}_{L}+m-\int_{X}\left(b(x)+\hat{s}\left(x, y_{L}\right)\right) \delta\left(x \mid y_{L}\right) d x\right],
\end{aligned}
$$

since $m \int_{X_{L}} \delta\left(x \mid y_{H}\right) d x \geq 0$. Using the fact that $P_{1} \bar{a}_{H}+\left(1-P_{1}\right) \bar{a}_{L}=\mathbb{E}(a)$, one can rewrite the above expression as

$$
\begin{aligned}
\Pi^{*} \geq & \Pi+\mathbb{E}(a)+m-P_{1}\left[\int_{X_{H}} b(x)+\int_{X_{L}}\left(\bar{a}_{H}+m\right)\right] \delta\left(x \mid y_{H}\right) d x \\
& -\left(1-P_{1}\right) \int_{X} b(x) \delta\left(x \mid y_{L}\right) d x .
\end{aligned}
$$


Step 5. Hence, to prove $\Pi^{*} \geq \Pi$ it is enough to show that

$$
\begin{aligned}
\mathbb{E}(a)+m \geq & P_{1}\left[\int_{X_{H}} b(x) \delta\left(x \mid y_{H}\right) d x+\int_{X_{L}}\left(\bar{a}_{H}+m\right) \delta\left(x \mid y_{H}\right) d x\right] \\
& +\left(1-P_{1}\right) \int_{X} b(x) \delta\left(x \mid y_{L}\right) d x .
\end{aligned}
$$

The right-hand side of (A.7) can be written as

$$
\begin{aligned}
& \int_{X_{H}} b(x)\left[P_{1} \delta\left(x \mid y_{H}\right)+\left(1-P_{1}\right) \delta\left(x \mid y_{L}\right)\right] d x \\
& \quad+P_{1} \int_{X_{L}}\left(\bar{a}_{H}+m\right) \delta\left(x \mid y_{H}\right) d x+\left(1-P_{1}\right) \int_{X_{L}}\left(\bar{a}_{L}+m\right) \delta\left(x \mid y_{L}\right) d x .
\end{aligned}
$$

Now,

$$
\begin{aligned}
& \int_{X_{H}} b(x)\left[P_{1} \delta\left(x \mid y_{H}\right)+\left(1-P_{1}\right) \delta\left(x \mid y_{L}\right)\right] d x=\int_{X_{H}} b(x) \delta(x) d x \\
& \quad=\int_{X_{H}}(\mathbb{E}(a \mid x)+m) \delta(x) d x
\end{aligned}
$$

(where $\delta(x)$ is the total probability of receiving the signal $x$ under the disclosure policy $\delta$ ) and

$$
\begin{aligned}
P_{1} & \int_{X_{L}}\left(\bar{a}_{H}+m\right) \delta\left(x \mid y_{H}\right) d x+\left(1-P_{1}\right) \int_{X_{L}}\left(\bar{a}_{L}+m\right) \delta\left(x \mid y_{L}\right) d x \\
& =\int_{X_{L}}\left[\left(\bar{a}_{H}+m\right) \frac{P_{1} \delta\left(x \mid y_{H}\right)}{\delta(x)}+\left(\bar{a}_{L}+m\right) \frac{\left(1-P_{1}\right) \delta\left(x \mid y_{L}\right)}{\delta(x)}\right] \delta(x) d x \\
& =\int_{X_{L}}\left[\left(\bar{a}_{H}+m\right) \operatorname{Pr}\left(y_{H} \mid x\right)+\left(\bar{a}_{L}+m\right) \operatorname{Pr}\left(y_{L} \mid x\right)\right] \delta(x) d x \\
& =\int_{X_{L}}\left[\sum_{y_{1}} \mathbb{E}\left(a \mid x, y_{1}\right) \operatorname{Pr}\left(y_{1} \mid x\right)+m\right] \delta(x) d x \\
& =\int_{X_{L}}(\mathbb{E}(a \mid x)+m) \delta(x) d x .
\end{aligned}
$$

So, the right-hand side of Equation (A.7) is equal to

$$
\int_{X_{H}}(\mathbb{E}(a \mid x)+m) \delta(x) d x+\int_{X_{L}}(\mathbb{E}(a \mid x)+m) \delta(x) d x=\mathbb{E}(a)+m .
$$


Hence, the condition (A.7) holds with equality. Note that $\Pi^{*}>\Pi$ if $\int_{X_{L}} \delta\left(x \mid y_{H}\right) d x>0$, i.e., if under $\delta$ the high-type agent faces a bid equal to $\bar{a}_{L}+m$ with nonzero probability.

Proof of Proposition 2. Recall that short-term performance contract is a special case of long-term complete contract. Hence, it is enough to show that under condition (i)-(iii), the optimal short-term performance contract with full transparency yields the same profit to $F$ as the optimal long-term complete contract.

Step 1. Proposition 1 suggests that the optimal long-term complete contract induces full transparency under a perfectly competitive raider market. The profit to $F$ under this contract is

$$
\Pi^{L}=\mathbb{E}_{y_{1}}\left[y_{1}-w_{1}\left(y_{1}\right)-\int_{X} \hat{s}\left(x, y_{1}\right) \delta\left(x \mid y_{1}\right) d x\right] .
$$

When $A$ is risk neutral, under the optimal long-term contract, the $(I R)$ constraint of $A$ implies

$$
\mathbb{E}_{y_{1}}\left[\left(\bar{a}_{i}+m\right)+w_{1}\left(y_{1}\right)+\int_{X} \hat{s}\left(x, y_{1}\right) \delta\left(x \mid y_{1}\right) d x\right]=\psi .
$$

Hence, (A.7) can be written as $\Pi^{L}=\mathbb{E} y_{1}-(\psi-(\mathbb{E}(a)+m))$.

Step 2. Consider the short-term performance contract with full transparency where the first-period wage $w_{1}^{*}\left(y_{1}\right)$ is given as

$$
\begin{aligned}
& w_{1}^{*}\left(y_{H}\right)=\psi+\frac{\left(1-P_{1}\right) \psi}{\Delta P}-\left(\bar{a}_{H}+m\right), \\
& w_{1}^{*}\left(y_{L}\right)=\psi-\frac{P_{1} \psi}{\Delta P}-\left(\bar{a}_{L}+m\right),
\end{aligned}
$$

and the second-period wage $\hat{w}_{2}^{*}=0$. These wage payments are feasible as $A$ does not face any liquidity constraint. By construction, $(I C)$ and $(I R)$ constraint of $A$ will bind. Hence, under this contract, $A$ faces the same incentives and earns the same rent as in the case of the optimal long-term complete contract. Finally, observe that $F$ 's profit under this contract is

$$
\Pi^{S}=\mathbb{E}_{y_{1}}\left[y_{1}-w_{1}^{*}\left(y_{1}\right)\right]=\mathbb{E} y_{1}-(\psi-(\mathbb{E}(a)+m))=\Pi^{L} .
$$

Proof of Proposition 3. Case a: Short-term Performance contracts: The first part of the proposition can be proved in the following way.

Consider a optimal short-term performance contract that discloses information using the policy $\delta=\left(\alpha_{H}, \alpha_{L}\right)$. Without loss of generality assume that $\delta$ is such that $\bar{a}_{L}=b\left(x_{L}\right)<b\left(x_{H}\right)=\bar{a}_{H}$. Let the first-period wage be $w_{1}\left(y_{1}\right)$ and as $b\left(x_{L}\right)=\bar{a}_{L}$, optimality requires $\hat{w}_{2}\left(x_{L}, y_{H}\right)=\bar{a}_{L}$. The profit to $F$ under this contract is

$$
\Pi=\mathbb{E}\left(y_{1}-w_{1}\left(y_{1}\right)\right)+P_{1}\left(\bar{a}_{H}-\bar{a}_{L}\right)\left(1-\alpha_{H}\right) .
$$


Consider another short-term performance contract where no information is disclosed, i.e., signals are pure noise. Hence under this contract $\mathbb{E}(a \mid x)=\mathbb{E}(a) \forall x \in$ $\left\{x_{L}, x_{H}\right\}$. As $\mathbb{E}(a)>\bar{a}_{H}-P_{1} m$, upon receiving any signal, $b=\bar{a}_{H}$. Let $w_{1}^{*}\left(y_{1}\right)$ be the first-period wages given by (A.9)

$$
\begin{aligned}
& \bar{a}_{H}+w_{1}^{*}\left(y_{H}\right)=w_{1}\left(y_{H}\right)+\bar{a}_{H} \alpha_{H}+\bar{a}_{L}\left(1-\alpha_{H}\right), \\
& \bar{a}_{H}+w_{1}^{*}\left(y_{L}\right)=w_{1}\left(y_{L}\right)+\bar{a}_{H} \alpha_{L}+\bar{a}_{L}\left(1-\alpha_{L}\right) .
\end{aligned}
$$

By construction, this contract leaves agent's incentives and expected utility unaltered compared to the initial case. As there is turnover for all types of the agent, with an abuse of notation, $F$ 's profit under this contract is

$$
\Pi^{*}=\mathbb{E}\left(y_{1}-w_{1}^{*}\left(y_{1}\right)\right)
$$

I claim $\Pi^{*} \geq \Pi$. To see this, note that

$$
\Pi^{*} \geq \Pi \Leftrightarrow \mathbb{E}\left(w_{1}\left(y_{1}\right)-w_{1}^{*}\left(y_{1}\right)\right) \geq P_{1}\left(\bar{a}_{H}-\bar{a}_{L}\right)\left(1-\alpha_{H}\right) .
$$

But (A.9) implies

$$
\begin{aligned}
\mathbb{E}\left(w_{1}\left(y_{1}\right)-w_{1}^{*}\left(y_{1}\right)\right) & =\left(\bar{a}_{H}-\bar{a}_{L}\right)\left[P_{1}\left(1-\alpha_{H}\right)+\left(1-P_{1}\right)\left(1-\alpha_{L}\right)\right] \\
& >P_{1}\left(\bar{a}_{H}-\bar{a}_{L}\right)\left(1-\alpha_{H}\right) .
\end{aligned}
$$

Hence the proof.

To prove the second part I proceed as follows.

Step 1. If $\mathbb{E}(a)<\bar{a}_{H}-P_{1} m$ then under any disclosure policy $\delta$ it is never the case that $b\left(x_{L}\right)=b\left(x_{H}\right)=\bar{a}_{H}$. If $\mathbb{E}(a \mid x)>\bar{a}_{H}-P_{1} m \forall x \in\left\{x_{L}, x_{H}\right\}$ then it must be the case that $\mathbb{E}(a)>\bar{a}_{H}-P_{1} m$; a contradiction. Without loss of generality I assume that $\bar{a}_{L}=b\left(x_{L}\right) \leq b\left(x_{H}\right)$.

Step 2. Consider the disclosure policy $\delta^{*}$ where $\alpha_{H}=1$ and $\alpha_{L}=\alpha_{L}^{*}$ such that the following equation is satisfied:

$$
\mathbb{E}\left(a \mid x_{H}\right)=\bar{a}_{H}-P_{1} m
$$

Note that $\alpha_{L}^{*}>0$ and there is turnover for both types. I claim that $\delta^{*}$ is the optimal disclosure policy.

Step 3. Given any disclosure policy $\hat{\delta}=\left(\hat{\alpha}_{H}, \hat{\alpha}_{L}\right)\left(\neq \delta^{*}\right), \delta^{*}$ yields a higher payoff to the firm. The argument is as follows. It is already noted that under $\hat{\delta}$, either $b\left(x_{L}\right)=b\left(x_{H}\right)=\bar{a}_{L}$ or $\bar{a}_{L}=b\left(x_{L}\right)<b\left(x_{H}\right)=\bar{a}_{H}$. I shall consider the case where $b\left(x_{L}\right)<b\left(x_{H}\right)$. The argument for the other case is similar.

Consider the optimal short-term performance contract with disclosure policy $\hat{\delta}$. Let the associated first-period wages be $w_{1}\left(y_{1}\right)$. By virtue of optimality of the contract and the bids of the raiders, $\hat{w}_{2}\left(x_{L}, y_{H}\right)=\bar{a}_{L}$. The profit to $F$ under this contract is 


$$
\hat{\Pi}=\mathbb{E}\left(y_{1}-w_{1}\left(y_{1}\right)\right)+P_{1}\left(\bar{a}_{H}-\bar{a}_{L}\right)\left(1-\hat{\alpha}_{H}\right) .
$$

I replace the above contract by another one with the disclosure policy $\delta^{*}$ and the first-period wage $w_{1}^{*}\left(y_{1}\right)$ is given by (A.11)

$$
\begin{aligned}
\bar{a}_{H}+w_{1}^{*}\left(y_{H}\right) & =w_{1}\left(y_{H}\right)+\hat{\alpha}_{H} \bar{a}_{H}+\left(1-\hat{\alpha}_{H}\right) \bar{a}_{L}, \\
\alpha_{L}^{*} \bar{a}_{H}+\left(1-\alpha_{L}^{*}\right) \bar{a}_{L}+w_{1}^{*}\left(y_{L}\right) & =w_{1}\left(y_{L}\right)+\hat{\alpha}_{L} \bar{a}_{H}+\left(1-\hat{\alpha}_{L}\right) \bar{a}_{L} .
\end{aligned}
$$

Again, by construction, the agent's payoff is the same conditional on the realized output. Hence at the new disclosure policy along with the wages $w_{1}^{*}\left(y_{1}\right)$, the $(I C)$ and $(I R)$ constraints are satisfied. The profit of the firm under the new contract (again, with an abuse of notation) is

$$
\Pi^{*}=\mathbb{E}\left(y_{1}-w_{1}^{*}\left(y_{1}\right)\right) .
$$

Step 4. First, note that $\alpha_{L}^{*} \geq \hat{\alpha}_{L}$. The argument is the following. ${ }^{35}$ By definition,

$$
\mathbb{E}_{\hat{\delta}}\left(a \mid x_{H}\right) \geq \mathbb{E}_{\delta^{*}}\left(a \mid x_{H}\right)=\bar{a}_{H}-P_{1} m
$$

or

$$
\bar{a} \mu_{\hat{\delta}}\left(\bar{a} \mid x_{H}\right)+\underline{a} \mu_{\hat{\delta}}\left(\underline{a} \mid x_{H}\right) \geq \bar{a} \mu_{\delta^{*}}\left(\bar{a} \mid x_{H}\right)+\underline{a} \mu_{\delta^{*}}\left(\underline{a} \mid x_{H}\right)
$$

or (using the fact $\left.\mu_{\delta}\left(\bar{a} \mid x_{H}\right)=1-\mu_{\delta}\left(\underline{a} \mid x_{H}\right)\right)$

$$
\mu_{\hat{\delta}}\left(\bar{a} \mid x_{H}\right) \geq \mu_{\delta^{*}}\left(\bar{a} \mid x_{H}\right) .
$$

As $\mu\left(\bar{a} \mid x_{H}\right)$ is increasing in $\alpha_{H}$ and decreasing in $\alpha_{L}$, from (A.12) it follows that $\alpha_{L}^{*} \geq \hat{\alpha}_{L}$ as $\alpha_{H}=1$ in $\delta^{*}$.

Step 5. Finally, I argue that $\Pi^{*} \geq \Pi$. To see this, note that

$$
\Pi^{*} \geq \hat{\Pi} \Leftrightarrow \mathbb{E}\left(w_{1}\left(y_{1}\right)-w_{1}^{*}\left(y_{1}\right)\right) \geq P_{1}\left(\bar{a}_{H}-\bar{a}_{L}\right)\left(1-\hat{\alpha}_{H}\right) .
$$

Now, by (A.11)

$$
\begin{aligned}
\mathbb{E}\left(w_{1}\left(y_{1}\right)-w_{1}^{*}\left(y_{1}\right)\right) & =\left(\bar{a}_{H}-\bar{a}_{L}\right)\left[P_{1}\left(1-\hat{\alpha}_{H}\right)+\left(1-P_{1}\right)\left(\alpha_{L}^{*}-\hat{\alpha}_{L}\right)\right] \\
& >P_{1}\left(\bar{a}_{H}-\bar{a}_{L}\right)\left(1-\hat{\alpha}_{H}\right) .
\end{aligned}
$$

The last inequality follows from the fact that $\alpha_{L}^{*}>\hat{\alpha}_{L}$.

CASE B: LONG-TERM COMPLETE CONTRACTS: As this proof is similar to the former one, I shall only provide a sketch here.

\footnotetext{
${ }^{35}$ I define $\mathbb{E}_{\delta}$ as the expectation operator when the disclosure policy is $\delta$; similarly for $\mu_{\delta}$.
} 
Consider the case $\mathbb{E}(a)>\bar{a}_{H}-P_{1} m$. Given any candidate solution to the optimal long-term contracting problem, I propose the following contract: I keep the first-period wage the same as before and no information is disclosed to the raiders. In addition, suppose that $F$ also generates a signal (not revealed to the raiders) according to the initial disclosure policy. The period-two wages and severance payments of $A,\left(w_{2}^{\prime \prime}, s^{\prime \prime}\right)$, are based on the realized $x$ values. $F$ sets $w_{2}^{\prime \prime}=s^{\prime \prime}=\hat{w}_{2}^{\prime \prime}=\hat{s}^{\prime \prime}$, where $\hat{s}^{\prime \prime}$ is given by the Equation (A.13)

$$
\bar{a}_{H}+\hat{s}^{\prime \prime}\left(x, y_{1}\right)=\max \left\{b(x)+\hat{s}\left(x, y_{1}\right), \hat{w}_{2}\left(x, y_{1}\right)\right\} \forall x \in X .
$$

Now, by arguments similar to the proof of Proposition 3 it can be shown that firm's payoff associated with this equilibrium is higher than the payoff associated with the initial equilibrium.

For the case $\mathbb{E}(a)<\bar{a}_{H}-P_{1} m$ the argument is again the same as in Proposition 3. Given any long-term complete contract with an arbitrary disclosure policy, replace it with the following one. Keep first-period wages the same and set the disclosure policy to be $\delta^{*}=\left(\alpha_{H}=1, \alpha_{L}=\alpha_{L}^{*}\right)$ (where $\alpha_{L}^{*}$ is as defined in (A.10)). In addition, suppose $F$ draws another signal $x \in X$ (not revealed to the raiders) according to the initial disclosure policy. The period-two wages and severance payments of $A,\left(w_{2}^{\prime \prime \prime}, s^{\prime \prime \prime}\right)$, are based on the realized $x$ values. $F$ sets $w_{2}^{\prime \prime \prime}=s^{\prime \prime \prime}=\hat{w}_{2}^{\prime \prime \prime}=$ $\hat{s}^{\prime \prime \prime}$ such that the agent's payoff is the same for every output-signal realization.

Now by the same argument as before the profit is higher under this contract.

Proof of Corollary 2. Recall that $\alpha_{L}^{*}$ solves $\mathbb{E}\left(a \mid x_{H}\right)=\bar{a}_{H}-P_{1} m$ when $\alpha_{H}=1$. The result follows from the fact that $\mathbb{E}\left(a \mid x_{H}\right)$ is decreasing in $\alpha_{L}$.

Proof of Proposition 4. The "if" part of the result is already proven in the text. To prove the "only if" part, first consider condition (i) in $\left(5^{\prime}\right)$.

It is enough to show that if $\left(P_{1}-P_{0}\right)\left(\bar{a}_{H}-\bar{a}_{L}\right) \leq \psi$ then even if $A$ faces a liquidity constraint, the profit to $F$ under the optimal short-term performance contract with full disclosure is at least as large as the profit associated under an optimal short-term contract with an arbitrary disclosure policy. This proof is similar to the proof of Proposition 1.

Step 1. Consider an optimal short-term contract with an arbitrary disclosure policy $\delta$ that is a feasible solution to $\mathcal{P}$ when $A$ faces a liquidity constraint. Let the associated period-one wage be $w_{1}\left(y_{1}\right) \geq 0$. Define $X_{H} \subseteq X$ and $X_{L}=X \backslash X_{H}$ as in Proposition 1. By virtue of optimality, given the bidding strategy of the raiders, $\hat{w}_{2}\left(y_{H}, x\right)=\bar{a}_{L}+m=b(x) \forall x \in X_{L}$. The profit to $F$ under this contract is

$$
\begin{aligned}
\Pi= & P_{1}\left(y_{H}-w_{1}\left(y_{H}\right)\right)+\left(1-P_{1}\right)\left(y_{L}-w_{1}\left(y_{L}\right)\right) \\
& +P_{1} \int_{X_{L}}\left(\bar{a}_{H}-\left(\bar{a}_{L}+m\right)\right) \delta\left(x \mid y_{H}\right) d x .
\end{aligned}
$$


Step 2. I replace this contract by another short-term performance contract with full disclosure where the first-period wage, $w_{1}^{*}\left(y_{1}\right)$, is given by the following equations:

$$
\begin{aligned}
w_{1}^{*}\left(y_{H}\right)+\bar{a}_{H}+m= & w_{1}\left(y_{H}\right)+\int_{X_{H}} b(x) \delta\left(x \mid y_{H}\right) d x \\
& +\int_{X_{L}}\left(\bar{a}_{L}+m\right) \delta\left(x \mid y_{H}\right) d x, \\
w_{1}^{*}\left(y_{L}\right)+\bar{a}_{L}+m= & w_{1}\left(y_{L}\right)+\int_{X_{H}} b(x) \delta\left(x \mid y_{L}\right) d x \\
& +\int_{X_{L}}\left(\bar{a}_{L}+m\right) \delta\left(x \mid y_{L}\right) d x .
\end{aligned}
$$

By construction, $A$ gets the same expected utility and faces the same incentives as in the initial contract.

Step 3. Equation (A.15) implies $w_{1}^{*}\left(y_{L}\right) \geq w_{1}\left(y_{L}\right) \geq 0$ as $\bar{a}_{L}+m \leq$ $\int_{X_{H}} b(x) \delta\left(x \mid y_{L}\right) d x+\int_{X_{L}}\left(\bar{a}_{L}+m\right) \delta\left(x \mid y_{L}\right) d x$. I also claim that $w_{1}^{*}\left(y_{H}\right) \geq 0$. As the initial contract is a feasible one and in the new contract $A$ faces the same incentives by construction, it must be the case that

$$
\begin{aligned}
& \left(P_{1}-P_{0}\right)\left[w_{1}^{*}\left(y_{H}\right)+b\left(x_{H}\right)-\left(w_{1}^{*}\left(y_{L}\right)+b\left(x_{L}\right)\right)\right] \\
& \quad=\left(P_{1}-P_{0}\right)\left[\left(w_{1}^{*}\left(y_{H}\right)-w_{1}^{*}\left(y_{L}\right)\right)+\left(\bar{a}_{H}-\bar{a}_{L}\right)\right] \\
& \quad \geq \psi .
\end{aligned}
$$

As $\left(P_{1}-P_{0}\right)\left(\bar{a}_{H}-\bar{a}_{L}\right) \leq \psi$, I conclude that $w_{1}^{*}\left(y_{H}\right)-w_{1}^{*}\left(y_{L}\right) \geq 0$ or $w_{1}^{*}\left(y_{H}\right) \geq$ $w_{1}^{*}\left(y_{L}\right) \geq 0$. Hence $w_{1}^{*}\left(y_{1}\right)$ as defined above is feasible even when $A$ faces a liquidity constraint.

Step 4. Profit to $F$ under the new contract following $y_{1}=y_{L}$ is

$$
\begin{aligned}
\Pi_{L}^{*} & =\left(y_{L}-w_{1}^{*}\left(y_{L}\right)\right) \\
& =y_{L}-w_{1}\left(y_{L}\right)-\int_{X_{H}} b(x) \delta\left(x \mid y_{L}\right) d x-\int_{X_{L}}\left(\bar{a}_{L}+m\right) \delta\left(x \mid y_{L}\right) d x+\bar{a}_{L}+m
\end{aligned}
$$

and following $y_{1}=y_{H}$ is

$$
\begin{aligned}
\Pi_{H}^{*}= & \left(y_{H}-w_{1}^{*}\left(y_{H}\right)\right) \\
= & y_{H}-w_{1}\left(y_{H}\right)-\int_{X_{H}} b(x) \delta\left(x \mid y_{H}\right) d x-\int_{X_{L}}\left(\bar{a}_{L}+m\right) \delta\left(x \mid y_{H}\right) d x+\bar{a}_{H}+m \\
> & y_{H}-w_{1}\left(y_{H}\right)-\int_{X_{H}} b(x) \delta\left(x \mid y_{H}\right) d x \\
& +\int_{X_{L}}\left\{\bar{a}_{H}-\left(\bar{a}_{L}+m\right)\right\} \delta\left(x \mid y_{H}\right) d x-\int_{X_{L}}\left(\bar{a}_{H}+m\right) \delta\left(x \mid y_{H}\right) d x+\bar{a}_{H}+m .
\end{aligned}
$$


Step 5. The profit to $F$ under the new contract is

$$
\begin{aligned}
\Pi^{*}= & P_{1} \Pi_{H}^{*}+\left(1-P_{1}\right) \Pi_{L}^{*} \\
\geq & P_{1}\left(y_{H}-w_{1}\left(y_{H}\right)\right)+\left(1-P_{1}\right)\left(y_{L}-w_{1}\left(y_{L}\right)\right) \\
& +P_{1}\left[\bar{a}_{H}+m-\int_{X_{H}} b(x) \delta\left(x \mid y_{H}\right) d x\right. \\
& \left.\quad+\int_{X_{L}}\left\{\bar{a}_{H}-\left(\bar{a}_{L}+m\right)\right\} \delta\left(x \mid y_{H}\right) d x-\int_{X_{L}}\left(\bar{a}_{H}+m\right) \delta\left(x \mid y_{H}\right) d x\right] \\
& +\left(1-P_{1}\right)\left[\bar{a}_{L}+m-\int_{X_{H}} b(x) \delta\left(x \mid y_{L}\right) d x-\int_{X_{L}}\left(\bar{a}_{L}+m\right) \delta\left(x \mid y_{L}\right) d x\right] .
\end{aligned}
$$

Using the fact that $P_{1} \bar{a}_{H}+\left(1-P_{1}\right) \bar{a}_{L}=\mathbb{E}(a)$, the above expression can be written as

$$
\begin{aligned}
\Pi^{*} \geq & \Pi+\mathbb{E}(a)+m-P_{1}\left[\int_{X_{H}} b(x) \delta\left(x \mid y_{H}\right) d x+\int_{X_{L}}\left(\bar{a}_{H}+m\right) \delta\left(x \mid y_{H}\right) d x\right] \\
& -\left(1-P_{1}\right)\left[\int_{X_{H}} b(x) \delta\left(x \mid y_{L}\right) d x+\int_{X_{L}}\left(\bar{a}_{L}+m\right) \delta\left(x \mid y_{L}\right)\right] .
\end{aligned}
$$

Hence, to prove $\Pi^{*} \geq \Pi$ it is enough to show that

$$
\begin{aligned}
\mathbb{E}(a)+m \geq & P_{1}\left[\int_{X_{H}} b(x) \delta\left(x \mid y_{H}\right) d x+\int_{X_{L}}\left(\bar{a}_{H}+m\right) \delta\left(x \mid y_{H}\right) d x\right] \\
& +\left(1-P_{1}\right)\left[\int_{X_{H}} b(x) \delta\left(x \mid y_{L}\right) d x+\int_{X_{L}}\left(\bar{a}_{L}+m\right) \delta\left(x \mid y_{L}\right)\right] .
\end{aligned}
$$

But in Step 5 of the proof of Proposition 1, I have already shown that the above condition is true.

This observation completes the proof.

Consider condition (ii) now. I have already shown that condition (i) is sufficient to induce full disclosure. Therefore I only need to consider the case

$$
\left(P_{1}-P_{0}\right)\left(\bar{a}_{H}-\bar{a}_{L}\right)>\psi \quad \text { but } \quad \mathbb{E}(a)+m \leq \psi
$$

Step 1. Consider any feasible solution to the optimal contracting problem with liquidity constraint where disclosure is partial. Let the first-period wage be $w_{1}\left(y_{1}\right) \geq 0$. Again, define $X_{H} \subseteq X$ and $X_{L}=X \backslash X_{H}$ as before. By virtue of optimality, given the bidding strategy of the raiders, $\hat{w}_{2}\left(y_{H}, x\right)=\bar{a}_{L}+m=b(x) \forall x \in X_{L}$. The $(I C)$ and $(I R)$ constraints under such a solution are

$$
\Delta_{y_{1}}\left[w_{1}\left(y_{1}\right)+\int_{X_{H}} b(x) \delta\left(x \mid y_{1}\right) d x+\int_{X_{L}}\left(\bar{a}_{L}+m\right) \delta\left(x \mid y_{1}\right) d x\right] \geq \frac{\psi}{\left(P_{1}-P_{0}\right)}
$$


and

(IR) $\quad \mathbb{E}_{y_{1}}\left[w_{1}\left(y_{1}\right)+\int_{X_{H}} b(x) \delta\left(x \mid y_{1}\right) d x+\int_{X_{L}}\left(\bar{a}_{L}+m\right) \delta\left(x \mid y_{1}\right) d x\right] \geq \psi$.

Rewrite the $(I R)$ constraint as

$\left(I R^{\prime}\right) \quad \mathbb{E}_{y_{1}} w_{1} \geq \psi-\mathbb{E}_{y_{1}}\left[\int_{X_{H}} b(x) \delta\left(x \mid y_{1}\right) d x+\int_{X_{L}}\left(\bar{a}_{L}+m\right) \delta\left(x \mid y_{1}\right) d x\right]$

As before, the profit to $F$ under this contract is

$$
\Pi=\mathbb{E}_{y_{1}}\left(y_{1}-w_{1}\left(y_{1}\right)\right)+P_{1}\left(\bar{a}_{H}-\left(\bar{a}_{L}+m\right)\right) \int_{X_{L}} \delta\left(x \mid y_{H}\right) d x .
$$

Step 2. Now, consider a short-term performance contract with full disclosure. Under $\left(5^{\prime \prime}\right)$ one can set $w_{1}\left(y_{H}\right)=w_{1}\left(y_{H}\right)=w^{*}$ where $w^{*}=\psi-(\mathbb{E}(a)+m)$. The profit to $F$ under this contract is

$$
\Pi^{*}=\mathbb{E} y_{1}-w^{*}
$$

It remains to show that

$$
\Pi^{*} \geq \Pi \Leftrightarrow \mathbb{E}_{y_{1}} w_{1}-w^{*} \geq P_{1}\left(\bar{a}_{H}-\left(\bar{a}_{L}+m\right)\right) \int_{X_{L}} \delta\left(x \mid y_{H}\right) d x
$$

Step 3. Plugging the $\left(I R^{\prime}\right)$ constraint in (A.16) and rearranging terms, one can rewrite (A.16) as

$$
\text { (A.17) } \begin{aligned}
\mathbb{E}(a)+m \geq & \mathbb{E}_{y_{1}}\left[\int_{X_{H}} b(x) \delta\left(x \mid y_{1}\right) d x+\int_{X_{L}}\left(\bar{a}_{L}+m\right) \delta\left(x \mid y_{1}\right) d x\right] \\
& +P_{1}\left(\bar{a}_{H}-\left(\bar{a}_{L}+m\right)\right) \int_{X_{L}} \delta\left(x \mid y_{H}\right) d x .
\end{aligned}
$$

Step 4. But using the expression for $\mathbb{E}(a)+m$ as derived in Step 5 of the proof of Proposition 1, the right-hand side of (A.17) can be rewritten as

$$
\mathbb{E}(a)+m-m P_{1} \int_{X_{L}} \delta\left(x \mid y_{H}\right) d x .
$$

Hence, the condition (A.17) is satisfied (the detailed calculations are given in Mukherjee (2005a).

Proof of Proposition 5. Consider and candidate solution $\left(w_{1}^{*}\left(y_{H}\right), w_{1}^{*}\left(y_{L}\right)\right.$, $\left.\alpha_{H}^{*}, \alpha_{L}^{*}\right)$ to the optimal contracting problem. I claim that $w_{1}^{*}\left(y_{H}\right)=w_{1}^{*}\left(y_{L}\right)=$ $\alpha_{L}^{*}=0$, and $\alpha_{H}^{*}<1$. The proof is given in the following steps: 
Step 1. At the optimal the (IC) constraint and the liquidity constraint for the low-type must bind. If not, $F$ can lower either $w_{1}^{*}\left(y_{H}\right)$ or $w_{1}^{*}\left(y_{L}\right)$ (or both) without violating any constraint and increase its profit. Therefore, for any given disclosure policy $\delta=\left(\alpha_{L}, \alpha_{H}\right)$, the optimal wages are $w_{1}^{*}\left(y_{L}\right)=0$ and $w_{1}^{*}\left(y_{H}\right)=$ $\max \left\{0, \frac{\psi}{\left(P_{1}-P_{0}\right)}-\left(\mathbb{E}\left(b \mid y_{H}\right)-\mathbb{E}\left(b \mid y_{L}\right)\right)\right\}$. It is routine to check that for any $\delta,(I R)$ is satisfied with these values of $w_{1}^{*}$.

Step 2. The optimal disclosure policy must also have $w_{1}^{*}\left(y_{H}\right)=0$. The argument is as follows: If $\frac{\psi}{\left(P_{1}-P_{0}\right)} \leq \mathbb{E}\left(b \mid y_{H}\right)-\mathbb{E}\left(b \mid y_{L}\right)$, trivially $w_{1}^{*}\left(y_{H}\right)=0$, and $(I C)$ is satisfied. I argue that $\frac{\psi}{\left(P_{1}-P_{0}\right)}>\mathbb{E}\left(b \mid y_{H}\right)-\mathbb{E}\left(b \mid y_{L}\right)$ cannot hold at the optimal. If so, the associated profit of $F$ is

$$
\begin{aligned}
\Pi= & \mathbb{E} y_{1}-P_{1}\left[\frac{\psi}{\left(P_{1}-P_{0}\right)}-\left(\mathbb{E}\left(b \mid y_{H}\right)-\mathbb{E}\left(b \mid y_{L}\right)\right)\right] \\
& +P_{1}\left(1-\alpha_{H}^{*}\right)\left(\bar{a}_{H}-\left(\bar{a}_{L}+m\right)\right) .
\end{aligned}
$$

Moreover, candidate solution must have $\alpha_{H}^{*}<1$ and/or $\alpha_{L}^{*}>0$. This is because condition (5) ensures that under full disclosure, $\frac{\psi}{\left(P_{1}-P_{0}\right)} \leq \mathbb{E}\left(b \mid y_{H}\right)-\mathbb{E}\left(b \mid y_{L}\right)$. But, $\Pi$ is increasing in $\alpha_{H}$ and decreasing in $\alpha_{L}$. Thus, $\frac{\psi}{\left(P_{1}-P_{0}\right)}>\mathbb{E}\left(b \mid y_{H}\right)-\mathbb{E}\left(b \mid y_{L}\right)$ cannot hold at the optimal.

Step 3. The optimal contract must have $\alpha_{L}^{*}=0$, and $\alpha_{H}^{*}<1$ such that (IC) is binding. Because $w_{1}^{*}\left(y_{H}\right)=w_{1}^{*}\left(y_{L}\right)=0$ at the optimal, the optimal disclosure policy maximizes $\Pi=P_{1}\left(1-\alpha_{H}^{*}\right)\left(\bar{a}_{H}-\left(\bar{a}_{L}+m\right)\right)$ subject to the $(I C)$ constraint. (Recall that I have already argued that $(I R)$ is satisfied when $(I C)$ is binding.) Now, when wages are set to 0 , the $(I C)$ constraint can be written as $\mathbb{E}\left(b \mid y_{H}\right)-\mathbb{E}\left(b \mid y_{L}\right)=$ $\psi /\left(P_{1}-P_{0}\right)$. Therefore, the optimal disclosure policy must involve the smallest $\alpha_{H}$ that satisfies the $(I C)$ constraint. Now, $\mathbb{E}\left(b \mid y_{H}\right)-\mathbb{E}\left(b \mid y_{L}\right)$ is increasing in $\alpha_{H}$ but decreasing in $\alpha_{L}$. Thus, the minimum feasible $\alpha_{H}$ is attainable when $\alpha_{L}^{*}=0$. Moreover, $\alpha_{H}^{*}<1$ since at full disclosure $\left(\alpha_{H}=1, \alpha_{L}=0\right)$ the $(I C)$ is slack, and $F$ can increase profit by reducing $\alpha_{H}$.

The comparative statics result follows directly from the fact that at the optimal $\alpha_{L}^{*}=0$ as $(I C)$ is binding. As $\psi$ increases, $\alpha_{H}^{*}$ must increase to satisfy $(I C)$.

This observation completes the proof.

Proof of Proposition 6. Optimality of full transparency requires $\delta^{*}=\left(\alpha_{H}=\right.$ $\left.1, \alpha_{L}=0\right)$ to be a solution for (8). Hence, it must be true that $\left(\partial \tilde{\Pi} / \partial \alpha_{H}\right)_{\delta=\delta^{*}} \geq 0$ and $\left(\partial \tilde{\Pi} / \partial \alpha_{L}\right)_{\delta=\delta^{*}} \leq 0 .{ }^{36}$ By differentiating $\tilde{\Pi}$ with respect to $\alpha_{H}$ and $\alpha_{L}$ at $\delta^{*}$, one arrives at ${ }^{37}$

\footnotetext{
${ }^{36}$ At $\delta=\delta^{*}$, consider only the left-hand derivative, i.e., $\frac{\partial \tilde{\Pi}}{\partial \alpha_{H}}=\lim _{k \uparrow 0} \frac{\tilde{\Pi}\left(\alpha_{H}+k\right)-\tilde{\Pi}\left(\alpha_{H}\right)}{k}$. This means that the value of the objective function may not increase as $\alpha_{H}$ decreases. Similarly, consider only the right hand derivative for $\frac{\partial \tilde{\Pi}}{\partial \alpha_{L}}$.

${ }^{37}$ Recall that $b_{L}=\bar{a}_{L}+m$ for all sufficiently small deviations from full transparency. Therefore, $\frac{\partial b_{L}}{\partial \alpha_{H}}=\frac{\partial b_{L}}{\partial \alpha_{L}}=0$ at full transparency.
} 


$$
\left.\frac{\partial \tilde{\Pi}}{\partial \alpha_{H}}\right|_{\delta=\delta^{*}}=\left.\frac{P_{1}}{r\left(V-u\left(w_{H}^{*}\right)\right)} \frac{\partial u_{2 H}}{\partial \alpha_{H}}\right|_{\delta=\delta^{*}}-P_{1}\left(\bar{a}_{H}-\left(\bar{a}_{L}+m\right)\right)
$$

and

$$
\left.\frac{\partial \tilde{\Pi}}{\partial \alpha_{L}}\right|_{\delta=\delta^{*}}=\frac{1}{r}\left[\left.\frac{P_{1}}{\left(V-u\left(w_{H}^{*}\right)\right)} \frac{\partial u_{2 H}}{\partial \alpha_{L}}\right|_{\delta=\delta^{*}}+\left.\frac{\left(1-P_{1}\right)}{\left(V-u\left(w_{L}^{*}\right)\right)} \frac{\partial u_{2 L}}{\partial \alpha_{L}}\right|_{\delta=\delta^{*}}\right]
$$

where $\left(\partial u_{2 H} / \partial \alpha_{H}\right)_{\delta=\delta^{*}}>0,\left(\partial u_{2 H} / \partial \alpha_{L}\right)_{\delta=\delta^{*}}<0$, and $\left(\partial u_{2 L} / \partial \alpha_{L}\right)_{\delta=\delta^{*}}>0$. Now, $\left.\frac{P_{1}}{r\left(V-u\left(w_{H}^{*}\right)\right)} \cdot \frac{\partial \tilde{\Pi}}{\partial \alpha_{H}}\right|_{\delta=\delta^{*}} \rightarrow \infty($ or 0$)$ as $r \rightarrow 0($ or $\infty)$. Since $\left.\frac{P_{1}}{r\left(V-u\left(w_{H}^{*}\right)\right)} \cdot \frac{\partial \tilde{\Pi}}{\partial \alpha_{H}}\right|_{\delta=\delta^{*}}$ is continuous, given the values of all other parameters, there exist a value of $r$, say $r^{*}$, such that $\left(\partial \tilde{\Pi} / \partial \alpha_{H}\right)_{\delta=\delta^{*}}=0$. Thus, there must exist values of $r$ in the neighborhood of $r^{*}$ such that $\left(\partial \tilde{\Pi} / \partial \alpha_{H}\right)_{\delta=\delta^{*}}<0$. Moreover, $\left(\partial \tilde{\Pi} / \partial \alpha_{L}\right)_{\delta=\delta^{*}}>$ or $<0$ depending on the relative magnitudes of $\left(\partial u_{2 H} / \partial \alpha_{L}\right)_{\delta=\delta^{*}}$ and $\left(\partial u_{2 L} / \partial \alpha_{L}\right)_{\delta=\delta^{*}}$.

This observation completes the proof.

Proof of Proposition 7. This proof is again similar to the proof of Proposition 1, and can be found in Mukherjee (2005a).

\section{REFERENCES}

Aghion, P., And P. Bolton, "Contracts as a Barrier to Entry," American Economic Review 77 (1987), 388-401.

Albano, G. L., And C. Leaver, "Transparency, Recruitment and Retention in Public Sector," Mimeo, University College London, 2004.

Autor, D., "Why Do Temporary Help Firms Provide Free General Skills Training?" Quarterly Journal of Economics 116 (2001), 1409-48.

Blanes-I-Vidal, J., "Authority, Delegation and The Winner's Curse," Mimeo, LSE and CEP, 2002.

Calzolari, G., and A. Pavan, "On the Optimality of Privacy in Sequential Contracting," Journal of Economics Theory 130 (2006), 168-204.

Dewatripont, M., I. JewitT, And J. Tirole, "The Economics of Career Concerns, Part I: Comparing Economic Structures," Review of Economic Studies 66 (1999a), 183-98.

,$- \ldots$, AND — - "The Economics of Career Concerns, Part II: Application to Missions and Accountability of Government Agencies," Review of Economic Studies 66 (1999b), 199-217.

Fallick, B., and C. Fleischman, "Employer-to-Employer Flows in the U.S. Labor Market: The Complete Picture of Gross Worker Flows," Finance and Economics Discussion Series Working Paper No. 2004-34, Federal Reserve Board, Washington, DC, 2004.

Fama, E., "Agency Problems and the Theory of the Firm," Journal of Political Economy 87 (1980), 288-307.

FARBER, H. S., "Mobility and Stability: The Dynamics of Job Change in Labor Markets," in O. Ashenfelter and D. Card, eds., Handbook of Labor Economics, Vol 3B (New York: Elsevier, 1999), 2439-83.

Gibbons, R., And K. J. Murphy, "Optimal Incentive Contracts in the Presence of Career Concerns: Theory and Evidence," Journal of Political Economy 100 (1992), 468-505.

Greenwald, B., "Adverse Selection in the Labor Market," Review of Economic Studies 53 (1986), 325-47. 
Holmstrom, B., "Managerial Incentive Problems: A Dynamic Perspective," Essays in Economics and Management in Honor of Lars Wahlbeck (Helsinki: Swedish School of Economics, 1982).

JeOn, S., "Moral Hazard and Reputational Concerns in Teams: Implications for Organizational Choice," International Journal of Industrial Organization 14 (1996), 297-315.

Koch, A., and E. Peyrache, "Aligning Ambition and Incentives: Optimal Contracts with Career Concerns," Mimeo, University of Bonn, 2003a.

— Toulouse, 2003b.

LazeAr, E., "Raids and Offer Matching," in R. Ehrenberg, ed., Research in Labor Economics, Vol. 8 (Greenwich, CT: JAI, 1986).

Loveman, W., And J. O'Connell, "HCL America." Harvard Business Review, Case \# 9396-030 (1996).

McAfee, P. R., And J. McMillan, “Auctions and Bidding,” Journal of Economic Literature 25 (1987), 699-738.

Milgrom, P. R., And R. Weber, “A Theory of Auction and Competitive Bidding,” Econometrica 50 (1982), 1089-122.

Muknerjee, A., "Skill Acquisition Under Implicit Contract," Mimeo, Northwestern University, 2003.

—_, "Career Concerns and Optimal Disclosure Policy," Working Paper No. 73, CSIO, Northwestern University, 2005a.

_ , "Essays in Economics of Organization," Ph.D. Dissertation, Northwestern University, 2005b.

Ortega, J., "Power in the Firm and Managerial Career Concerns," Journal of Economics and Management Strategy 12 (2003), 1-29.

Scharfstein, D. S., And J. C. Stein, "Herd Behavior and Investment," American Economic Review 80 (1990), 465-79.

Siter, K. E., AND M. D. Whinston, "On the Efficiency of Privately Stipulated Damages for Breach of Contract: Entry Barriers, Reliance, and Renegotiation," The RAND Journal of Economics 26 (1995), 180-202.

Waldman, M., "Job Assignments, Signaling, and Efficiency," The RAND Journal of Economics 15 (1984), 255-67.

— , "Up-or-Out Contracts: A Signaling Perspective," Journal of Labor Economics 8 (1990), 230-50.

ZÁbojník, J., And D. Bernhardt, "Corporate Tournaments, Human Capital Acquisition, and the Firm Size-wage Relation," Review of Economic Studies 68 (2001), 693-16. 